\title{
Microstructure and magnetic properties of NiZn ferrite prepared by ultrafast pulse electric current sintering without pressure
}

\section{Guixiang Liu (D 10761817@qq.com)}

Southwest University of Science and Technology https://orcid.org/0000-0003-0033-9824

\section{Bo DAl}

Southwest University of Science and Technology

\section{Yong REN}

Southwest University of Science and Technology

Kuibao ZHANG

Southwest University of Science and Technology

\section{Dengjian YE}

Southwest University of Science and Technology

\section{Chunfeng HU}

Southwest Jiaotong University

\section{Weitong ZHANG}

Southwest University of Science and Technology

\section{Shuai FU}

Southwest Jiaotong University

\section{Research Article}

Keywords: nickel-zinc ferrite, ultrafast pulse electric current sintering, Joule heating, rapid densification

Posted Date: May 4th, 2021

DOI: https://doi.org/10.21203/rs.3.rs-479427/v1

License: (1) (1) This work is licensed under a Creative Commons Attribution 4.0 International License. Read Full License 


\title{
Microstructure and magnetic properties of NiZn ferrite prepared by ultrafast pulse electric current sintering without pressure
}

\author{
Guixiang LIU a , Bo DAI a,*, Yong REN ${ }^{\text {a }}$, Kuibao ZHANG ${ }^{\text {a }}$, Dengjian YE ${ }^{\text {a }}$, Chunfeng HU, \\ Weitong ZHANG ${ }^{\text {a }}$, Shuai FU ${ }^{\text {b }}$ \\ ${ }^{a}$ State Key Laboratory of Environment-friendly Energy Materials, School of Materials Science and \\ Engineering, Southwest University of Science and Technology, Mianyang 621010, China \\ ${ }^{b}$ Key Laboratory of Advanced Technologies of Materials, Ministry of Education, School of \\ Materials Science and Engineering, Southwest Jiaotong University, Chengdu 610031, China
}

\begin{abstract}
Polycrystalline nickel-zinc ferrite ceramics were prepared within tens of seconds via ultrafast pulse electric current sintering without pressure. The phase composition and microstructure of the samples were characterized by X-ray diffraction and scanning electron microscopy, respectively. The static magnetic properties and Curie temperature of the samples were investigated by vibrating sample magnetometry. The main phase of the sintered sample was the same as that of the raw powder, and the maximum relative density of the sample reached $95.72 \%$. The densification and grain growth of the sample were accelerated through the synergistic effect of the energy concentration of pulse current heating and Joule heating that was generated by the sample. The grains at the edge of the sample were larger than those at the center, which was attributed to the uneven temperature distribution in a sintering sample. The slight differences in specific saturation magnetization and Curie temperature of the samples were attributed to the slight difference in sample phase composition that was caused by partial nickel-zinc ferrite decomposition and $\mathrm{Zn}$ volatilization during sintering. The inferred critical grain size between the dual- and mono-domain was $\sim 450 \mathrm{~nm}$. The ultrafast pulse electric current sintering technique has the advantages of a heating energy concentration, high heating rate and energy saving. The technique provides an effective approach to prepare compact and ultrafine grain ceramics rapidly.
\end{abstract}

Key words: nickel-zinc ferrite; ultrafast pulse electric current sintering; Joule heating; rapid densification 


\section{Introduction}

Ferrite is an oxide that contains iron and one or more other metals. The nickel-zinc (NiZn) ferrite with spinel structure is one of the typical representatives of soft magnetic materials. Because NiZn ferrite has the advantages of a simple preparation, high resistivity, low eddy current loss and good chemical properties, it is widely used in the telecommunications and high frequency power industries, such as inductors, transformers, isolators, magnetic amplifiers and transfer switches [1-5]. The magnetic properties of the ferrite depend on its chemical composition and microstructure [6,7]. In the spinel ferrite unit cell, tetrahedrons and octahedrons are formed by regular cubic close packing of the oxygen ions. NiZn ferrite is a mixed spinel, in which $\mathrm{Zn}^{2+}$ ions occupy the tetrahedral (A) sites, $\mathrm{Ni}^{2+}$ ions occupy the octahedral (B) sites, and $\mathrm{Fe}^{3+}$ ions occupy the $\mathrm{A}-$ and B-sites [8]. The magnetic moment of the A-sublattice is antiparallel to that of the B-sublattice. The magnetic moment of the NiZn ferrite is determined from the difference of the magnetic moments between the A- and B-sublattices [9]. The Curie temperature $\left(\mathrm{T}_{\mathrm{c}}\right)$ of the NiZn ferrite depends on the superexchange interaction between the A- and B-sublattices. In addition, the NiZn ferrite microstructure has an important influence on the coercivity $\left(\mathrm{H}_{\mathrm{c}}\right)$, ferromagnetic resonance linewidth, and permeability of the NiZn ferrite [5].

NiZn ferrite is commonly used in devices as ceramics that are processed into a certain shape. Sintering is a key step in ceramic preparation, which influences the ceramic microstructure. The conventional ceramic technique with a high temperature and long holding time increases the energy consumption significantly [10-12]. Furthermore, it leads to the volatilization of some components, which results in a composition instability and ferrite performance uncertainty because of the long holding time at a high temperature. To shorten the sintering time and/or to reduce the sintering temperature, extensive attention has been focused on the ceramic sintering technique. To date, many techniques, such as spark plasma sintering [13-17], electric current/field-assisted sintering [18-23], hot pressing sintering [24-26] and microwave sintering [27-32], are used for this purpose.

In this work, NiZn ferrite ceramics were prepared through ultrafast pulse electric current sintering (UPECS) without pressure. The raw material was $\mathrm{Ni}_{0.75} \mathrm{Zn}_{0.25} \mathrm{Fe}_{2} \mathrm{O}_{4}$ nanopowder without any additives. During the UPECS process, the sample was kept above $600^{\circ} \mathrm{C}$ for no more than $90 \mathrm{~s}$. 
The microstructure and magnetic properties of the prepared samples were investigated.

\section{Materials and Method}

A self-made nanopowder was used as the raw material. The preparation process and properties of the powder are provided in reference [18]. The phase of the raw powder was $\mathrm{Ni}_{0.75} \mathrm{Zn}_{0.25} \mathrm{Fe}_{2} \mathrm{O}_{4}$ (NiZn ferrite, JCPDS No. 52-0277), and its average crystallite size of $16 \mathrm{~nm}$ was estimated by using the Scherrer equation [33]. The raw powder was granular, and its particle size ranged from $10 \mathrm{~nm}$ to $25 \mathrm{~nm}$.

The sintered NiZn ferrite was prepared by using a pulse electric current sintering system (SPS-20T-10, Chenhua Co., Ltd., China). A schematic of the graphite die-punches setup that was used in the sintering system is shown in Fig. 1. The raw powder was placed into the graphite cavity that formed between the graphite die and punches. An axial pressure of $60 \mathrm{MPa}$ was applied to the powder in the graphite cavity for $1 \mathrm{~min}$. Then, the pressure was removed and a pulse direct current was applied to the die-punches-sample system. The sample was heated at a heating rate from $5^{\circ} \mathrm{C} / \mathrm{s}$ to $25^{\circ} \mathrm{C} / \mathrm{s}$. When the sample temperature reached the preset sintering temperature that ranged from $900^{\circ} \mathrm{C}$ to $1200^{\circ} \mathrm{C}$, the power supply was turned off, followed by a rapid cooling of the sample. A disc-shaped sintered sample with a diameter of $20 \mathrm{~mm}$ and a thickness of $\sim 3 \mathrm{~mm}$ was obtained. For comparison, a traditional non-pressure solid-phase sintering method was used to prepare the sintered samples with the same raw powder and prepressing conditions. The sintering process diagrams of the NiZn ferrite that was prepared by the UPECS method and the traditional method are shown in Fig. 2.

Phase analysis of the raw powder and the prepared ceramics at the center of the disc-shaped samples was obtained by XRD (X'Pert PRO, PANalytic, Netherlands) using $\mathrm{CuK}_{\alpha}$ radiation $(\lambda=$ $1.5406 \AA$ ) under the same XRD measurement conditions. The microstructures of the raw powder and ferrite ceramics were examined by field emission scanning electron microscopy (Zeiss Ultra 55, Germany). The average grain size of the sintered sample was estimated by a line intercept method on an SEM image. The static magnetic properties at room temperature and the Curie temperature of the samples were measured by using a vibrating sample magnetometer (Lake Shore 8607, America). The bulk density $\left(\mathrm{D}_{\mathrm{b}}\right)$ of the ferrite ceramics was calculated using a water boiling method based on 
Archimedes principle. The relative density $\left(\mathrm{D}_{\mathrm{r}}\right)$ and porosity $(\mathrm{P})$ of the sintered samples were calculated from equations (1) and (2), respectively:
$\mathrm{D}_{\mathrm{r}}=\frac{\mathrm{D}_{\mathrm{b}}}{\mathrm{D}_{\mathrm{x}}} \times 100 \%$
and $\quad P=\left(1-\frac{D_{b}}{D_{x}}\right) \times 100 \%$

where $\mathrm{D}_{\mathrm{x}}$ is the $\mathrm{X}$-ray density.

\section{Results and discussion}

\subsection{Phase crystal structure of samples}

Figure $3 \mathrm{a}$ and $\mathrm{b}$ shows the XRD patterns of the samples that were sintered by the UPECS method at a fixed heating rate of $25^{\circ} \mathrm{C} / \mathrm{s}$ while changing the sintering temperature, and at the fixed sintering temperature of $900^{\circ} \mathrm{C}$ while changing the heating rate, respectively. The diffraction peaks of all sintered samples were consistent with the standard diffraction peaks of the cubic spinel NiZn ferrite ( $\mathrm{Ni}_{0.75} \mathrm{Zn}_{0.25} \mathrm{Fe}_{2} \mathrm{O}_{4}$, JCPDS No. 52-0277). These peaks corresponded to the (111), (022), (113), (222), (004), (224), (333), and (044) planes of the NiZn ferrite. The diffraction peaks of the sintered NiZn ferrites were stronger and sharper than those of the raw powder because of the improved crystallization that was induced through high-temperature sintering, even though the sintering time was short (no holding time).

The precise lattice parameter (a) of the sample was obtained by extrapolation. Equation (3) can be derived from the Bragg equation and the expression of interplanar spacing in the cubic crystal:

$$
\mathrm{a}=\frac{\lambda \sqrt{H^{2}+K^{2}+L^{2}}}{2 \sin \theta}
$$

where $\lambda$ is the wavelength of the incident $\mathrm{X}$-ray in the XRD experiment; $\theta$ is the Bragg angle; $\mathrm{H}, \mathrm{K}$ and $L$ are the indices of the interference plane. The Nelson-Riley function $f(\theta)$ is used as the extrapolation function, which is expressed as [34]:

$$
\mathrm{f}(\theta)=\left(\frac{\cos ^{2} \theta}{\sin \theta}+\frac{\cos ^{2} \theta}{\theta}\right) / 2
$$

According to the XRD data of a sample, the lattice parameter values and $\mathrm{f}(\theta)$ of the sample were calculated from equations (3) and (4), respectively, and the $\mathrm{a}-\mathrm{f}(\theta)$ plot was constructed. The fitting linear a $-\mathrm{f}(\theta)$ plot was extrapolated to $\mathrm{f}(\theta)=0$ (i.e., $\theta=90^{\circ}$ ) and the intercept was the precise lattice 
parameter. The precise lattice parameter values of the samples are shown in Table 1. The difference in lattice parameters between the prepared and standard samples (Ni0.75Zn0.25Fe22 4 , JCPDS No. 52-0277: $\mathrm{a}=8.370 \AA$ ) was less than $0.05 \%$. The result indicated that the main phase of the sintered samples that was prepared by UPECS was $\mathrm{Ni}_{0.75} \mathrm{Zn}_{0.25} \mathrm{Fe}_{2} \mathrm{O}_{4}$.

\subsection{Microstructure of samples prepared by UPECS}

\subsubsection{Microstructure of samples prepared by UPECS at different sintering temperatures}

Figure 4 shows the SEM images of the NiZn ferrite sintered by UPECS at different temperatures when the heating rate was $25^{\circ} \mathrm{C} / \mathrm{s}$. The SEM images of the sintered samples at a depth of $500 \mu \mathrm{m}$ from the sample surface (marked as an edge) are shown in Fig. 4a-e and that of the center position (marked as the center) are shown in Fig. $4 \mathrm{f}-\mathrm{j}$. For the edge and center of the sample, the grain size of the NiZn ferrite increased gradually with the increase in sintering temperature from $900^{\circ} \mathrm{C}$ to $1200^{\circ} \mathrm{C}$. The average grain size, density and porosity of the sample that was sintered by the UPECS are shown in Table 1.

When the sintering temperature was $900^{\circ} \mathrm{C}$, the prepared sample was loose and the grains were small but nonuniform. The sample was composed of grain clusters, in which the grains were in contact with each other closely. Interconnected pores appeared between clusters (Fig. 4a and f), which resulted in a high sample porosity and low density. As the temperature increased to $1000^{\circ} \mathrm{C}$, the grains combined closely and the pores were reduced. However, the difference in grain size remained obvious (Fig. $4 \mathrm{~b}$ and g). When the sintering temperature reached $1050^{\circ} \mathrm{C}$, the porosity decreased further, the grain shape was regular and the grains gradually tended to be uniform (Fig. $4 \mathrm{c}$ and $\mathrm{h})$.

When the sintering temperature increased to $1100^{\circ} \mathrm{C}$, the grains of the sample became more uniform and the grain size increased further. The pore size at the junction of the grains increased (Fig. 4d and i), and round pores appeared on the grain surface (Fig. 4i). Many pores in the sample originated from the partial reduction of $\mathrm{Fe}^{3+}$ and $\mathrm{Zn}$ volatilization. At a low oxygen partial pressure and high temperature of $1100^{\circ} \mathrm{C}$, part of the $\mathrm{Fe}^{3+}$ was reduced, which caused partial NiZn ferrite decomposition to form $\mathrm{O}_{2}$ and $\mathrm{ZnO}$ (equation 5). The low oxygen partial pressure and high temperature environment were conducive to $\mathrm{ZnO}$ decomposition into $\mathrm{Zn}$ and $\mathrm{O}_{2}$, and $\mathrm{Zn}$ 
volatilization occurred because of its low boiling point of $907^{\circ} \mathrm{C}$ (equation 6).

$$
\begin{aligned}
& \mathrm{Ni}_{0.75} \mathrm{Zn}_{0.25} \mathrm{Fe}_{2} \mathrm{O}_{4} \rightarrow \frac{2}{3} \mathrm{Fe}_{3} \mathrm{O}_{4}+0.75 \mathrm{NiO}+0.25 \mathrm{ZnO}+\frac{1}{6} \mathrm{O}_{2} \uparrow \\
& \mathrm{ZnO} \rightarrow \mathrm{Zn}+0.5 \mathrm{O}_{2} \uparrow
\end{aligned}
$$

The $\mathrm{O}_{2}$ and $\mathrm{Zn}$ vapor that were produced in the reactions increased and/or expanded the pores in the sample, which resulted in the low density and high porosity of the sintered sample (Table 1). Although part of the NiZn ferrite decomposed at a high temperature and a low oxygen partial pressure, the NiZn ferrite decomposition was minimal because of the short UPECS sintering time and so the secondary phase was not detected by XRD. Therefore, the XRD patterns of the sintered samples indicated that the NiZn ferrite was the main phase (Fig. 3).

When the sintering temperature reached $1200^{\circ} \mathrm{C}$, the sample was dense and most of the sample grains were larger than $1 \mu \mathrm{m}$ (Fig. $4 \mathrm{e}$ and $\mathrm{j}$ ). The pores in the sample were large and they mainly converged at the junction of the multiple grains. The grain size (D) increased with the increase in sintering temperature, which was closely related to the sintering time $(\mathrm{t})$ and temperature $(\mathrm{T})$. The relationship between $\mathrm{D}, \mathrm{t}$ and $\mathrm{T}$ conformed to the crystal growth kinetics, as shown in equation (7) [35-37].

$$
\begin{aligned}
& \mathrm{D}^{\mathrm{n}}-\mathrm{D}^{0}=\mathrm{t} \cdot \mathrm{K}_{0} \cdot \exp (-\mathrm{Q} / \mathrm{RT}) \\
& \mathrm{D}^{\mathrm{n}} \approx \mathrm{t} \cdot \mathrm{K}_{0} \cdot \exp (-\mathrm{Q} / \mathrm{RT})
\end{aligned}
$$

where $\mathrm{n}$ is a grain growth exponent, $\mathrm{D}^{0}$ is the grain size before sintering, $\mathrm{Q}$ is the activation energy of the grain growth, and $\mathrm{R}$ is the gas constant. Because the $\mathrm{D}^{0}$ was very small and was ignored, equation (7) was simplified to equation (8). For similar reaction times, the energy in the sample increased with an increase in temperature and the grain boundary moved to reduce the interfacial energy and meet the minimum energy requirement. So, grains easily grew into large grains at a high temperature. Most pores in the sintered sample contained gases $\left(\mathrm{O}_{2}\right.$ and $\mathrm{Zn}$ vapor originated from part of the NiZn ferrite decomposition). The pressure in the small pores of the sample was higher than that of the big pores, which made small pores migrate to the large pores. During sintering, some pores were excluded from the sample through grain boundary diffusion, whereas other pores were not eliminated in time because of the short sintering time, and they converged at the junctions of the multiple grains. Therefore, with an increase in grain size, the pore size increased. 


\subsubsection{Microstructure of samples prepared by UPECS at different heating rates}

Figure 5 shows the SEM images of the samples that were sintered at $900^{\circ} \mathrm{C}$ through UPECS with different heating rates. SEM images of the edge of the samples are shown in Fig. 5a-c and those of the center of the samples are shown in Fig. $5 \mathrm{~d}-\mathrm{f}$. The average grain size, density and porosity of the sintered samples are shown in Table 1. For the edge and center of the sample, the grain size of the NiZn ferrite decreased and the porosity increased with an increase in heating rate from $5^{\circ} \mathrm{C} / \mathrm{s}$ to $25^{\circ} \mathrm{C} / \mathrm{s}$. The average grain size of the sample sintered at $5^{\circ} \mathrm{C} / \mathrm{s}$ ranged from $420 \mathrm{~nm}$ to $460 \mathrm{~nm}$, and the sample was dense and homogeneous (Fig. 5a and d). The sample that was sintered at $10^{\circ} \mathrm{C} / \mathrm{s}$ remained dense and its average grain size decreased slightly to $398-410 \mathrm{~nm}$, but the grains became uneven (Fig. $5 \mathrm{~b}$ and e). As the heating rate increased to $25^{\circ} \mathrm{C} / \mathrm{s}$, the sintered sample was porous and its grain size distribution was wide (Fig. 5c and f). The large grain exceeded 600 $\mathrm{nm}$ and the small grain was less than $100 \mathrm{~nm}$.

The above experimental results indicated that the NiZn ferrite samples were kept above $600^{\circ} \mathrm{C}$ for no more than $90 \mathrm{~s}$ during UPECS. The crystallization of the prepared sample was better than that of the raw powder, and the highest relative density of the sintered sample reached $95.72 \%$. Compared with the traditional sintering method with a high temperature for several hours [10-12], the rapid sample densification by UPECS was attributed to the heating mechanism in the pulse current sintering. The grain at the edge of the sample was larger than that at the center of the sample, which was related to the pulse current heating approach and the conductivity characteristics of the NiZn ferrite.

\subsection{Discussion on UPECS mechanism and microstructure inhomogeneity of NiZn ferrite}

\subsubsection{Discussion on the UPECS mechanism of NiZn ferrite}

A high current and low voltage is used in pulse current sintering, which can reduce the sintering time significantly because of the heating mechanism. Compared with the external heat source in the traditional sintering, the energy to heat the sample originates from Joule heat conduction from the graphite die-punches setup and the Joule heat that is generated by the NiZn ferrite during pulse current sintering. NiZn ferrite is a semiconductor material. Its conductivity $(\sigma)$ correlates with the Arrhenius equation, which is expressed as [38]: 
$\sigma=A \exp (-\triangle \mathrm{E} / 2 \mathrm{kT})$

where $\sigma_{0}$ is a constant that is related to the carrier concentration, $\triangle \mathrm{E}$ is the conductivity activation energy, $\mathrm{k}$ is the Boltzmann constant and $\mathrm{T}$ is the absolute temperature. According to equation (9), the NiZn ferrite conductivity increases with an increase in temperature.

Figure 6 shows a schematic diagram of the current flow path during sintering. Compared with graphite, NiZn ferrite was considered to be an insulator because of the low temperature and low density at the initial stage of sintering. The current deflected at the front end of the upper punch and flowed through the graphite die rather than directly through the sample in the cavity along the axial direction (Fig. 6a). The energy that heated the sample originated almost exclusively from the heat conduction of the Joule heat that was generated in the graphite die-punches setup at the initial sintering stage. Progress in sintering resulted in an increase in NiZn ferrite conductivity with an increase in temperature. The conductivity also increased with the increasing sample density. Therefore, part of the current flowed through the sample (Fig. 6b) and the sample itself generated Joule heat in the middle and final sintering stages. The sample temperature was elevated rapidly because of the synergistic effect of heating energy concentration of the current and the conductivity characteristic of the semiconductor NiZn ferrite.

During pulse current sintering, the Joule heat that was generated at the contact point between particles was important for NiZn ferrite grain growth and densification. Some particles contacted each other in the green compact. When the sample temperature was high enough, part of the current flowed through the particles that contacted each other (Fig. 7a) and a large amount of Joule heat was generated at the contact points, which made the particle surface layer melt immediately to form necks instantaneously. As the current continued to flow through the sample, a large amount of Joule heat was still generated at the necks, which increased the atom/molecule diffusion at the neck and promoted grain growth and densification of the sample. The Laplace stress (marked as P, Fig. 7b) appeared along with neck formation. The Laplace stress was a tensile stress for the necks, which increased the interaction between particles and results in the promotion of neck growth. However, the Laplace stress was a compressive stress for the pores near the necks, which caused the pores to shrink and led to rapid sample densification. The above results showed that a large amount of Joule 
heat and Laplace stress at the necks promoted NiZn ferrite densification and grain growth during pulse current sintering, which completed the NiZn ferrite sample sintering within tens of seconds.

\subsubsection{Discussion on the microstructure inhomogeneity of NiZn ferrite prepared by UPECS}

Figure 4 shows that when the heating rate was high $\left(25^{\circ} \mathrm{C} / \mathrm{s}\right)$, the grains at the edge of the sample that was obtained by the UPECS method were significantly larger than those at the center of the sample. The difference in grain size of the sample is shown in Fig. 8a and Table 1. The grain inhomogeneity in the sample originated from the uneven temperature distribution in the sample during sintering. In the early stage of UPECS, the heating energy for the sample originated only from the heat conduction of Joule heat that was generated in the graphite setup. The time that the sample was at a high temperature was short because the sample was heated to the sintering temperature fairly rapidly, followed by a turning off of the supply power and rapid sample cooling. During this short heat treatment, the temperature distribution in the sample was uneven at the early sintering stage. The temperature at the edge of the sample, which was in direct contact with the graphite setup, was higher than that at the center of the sample. The uneven temperature distribution in the sample led to an uneven current distribution in the sample in the middle and final sintering stages because of the characteristic of a negative temperature coefficient of resistivity of the NiZn ferrite (Fig. 6b). The Joule heat energy that was generated at different positions in the sample self was different, which aggravated the temperature difference between the center and edge of the sample. Generally, a high temperature promoted grain growth, so the grains at the edge of the sample were larger than those at the center of the sample because of the uneven temperature distribution in the sample. Although the temperature in the sample may be homogeneous because of heat conduction during the final sintering stage, the difference in grain size distribution that was caused during the earlier sintering stage was partially retained in the final sintered sample because of the short sintering time.

Figure 4, especially Fig. 4d and i shows that more pores existed at the center of the sample compared with those at the edge of the sample. The temperature at the edge of the sample was higher than that at the center of the sample, which yielded a better migration ability of the pores in the former. The pores at the edge of the sample were removed more easily from the sample by grain 
boundary diffusion than those at the center of the sample. Based on the above two reasons, fewer pores existed at the edge of the sample (Fig. 4d) compared with those at the center of the sample (Fig. 4i).

\subsubsection{Comparison of microstructure between samples sintered by different methods}

By using the same raw powder, prepressing conditions and at the sintering temperatures of $900^{\circ} \mathrm{C}$ and $1050^{\circ} \mathrm{C}$, NiZn ferrite samples were prepared by the UPECS method at a heating rate of $25^{\circ} \mathrm{C} / \mathrm{s}$ and by the traditional sintering method at a heating rate of $10^{\circ} \mathrm{C} / \mathrm{min}$, respectively. The sintering process diagrams are shown in Fig. 2. Figures 9 and 10 show the XRD patterns and SEM images of the center of the sintered samples, respectively. Figure 9 shows that the main phase of the samples sintered by the two methods was the same, which was the NiZn ferrite $\left(\mathrm{Ni}_{0.75} \mathrm{Zn}_{0.25} \mathrm{Fe}_{2} \mathrm{O}_{4}\right.$, JCPDS No. 52-0277). The crystallization of the sintered samples was better than that of the raw powder. Figure 10 shows that the samples that were sintered at $900^{\circ} \mathrm{C}$ were loose and the samples that were sintered at $1050^{\circ} \mathrm{C}$ were dense for both samples that were sintered by the two methods. The average grain size of the NiZn ferrite that was prepared by the UPECS method was slightly smaller than that of the NiZn ferrite that was prepared by the traditional sintering (Table 1) because of the short UPECS time. The experiment indicated that the NiZn ferrite with a similar density and crystallization was prepared within tens of seconds by the UPECS method, whereas traditional sintering requires several hours, which confirmed that NiZn ferrite densification and grain growth was accelerated by the UPECS technique.

\subsection{Magnetic properties of sintered samples prepared by UPECS}

Hysteresis loops of the raw powder and NiZn ferrite at the center of samples that were prepared by UPECS are shown in Fig. 11. These narrow loops exhibited characteristics that were typical of soft magnetic materials. For example, the coercivity $\left(\mathrm{H}_{\mathrm{c}}\right)$ and residual magnetization $\left(\mathrm{M}_{\mathrm{r}}\right)$ were small and the specific saturation magnetization $\left(M_{s}\right)$ was high (Fig. 11 and Table 1). $M_{s}$ is the intrinsic property of the magnetic materials, which is mainly related to its composition, crystallinity and particle size. The $\mathrm{M}_{\mathrm{s}}$ of the sintered sample was higher than that of the raw nanopowder. This behavior was attributed to the good crystallization of the sintered sample, which avoided/reduced the decrease in magnetic moment that was caused by the spin disorder on the nanoparticle surface. 
The $\mathrm{M}_{\mathrm{s}}$ of the sintered samples fluctuated slightly, which was attributed to a small difference in phase composition of the sintered samples because of the decomposition of a small amount of NiZn ferrite (equation 5) and $\mathrm{Zn}$ volatilization (equation 6) during the sintering.

The average grain size (D) dependence of $\mathrm{H}_{c}$ at the center of the samples that were prepared by the UPECS method is shown in Fig. 12. When the grain size of the sample increased from $294 \mathrm{~nm}$ to $1463 \mathrm{~nm}$, the $\mathrm{H}_{\mathrm{c}}$ of the sample increased first and then decreased. The sample $\mathrm{H}_{\mathrm{c}}$ reached the maximum value of 36.0 Oe when the average grain size was $450 \mathrm{~nm}$. According to the Stoner-Wohlfarth mono-domain theory [39], the magnetocrystalline anisotropy energy of the mono-domain grain increases with an increase in grain size, which occurs mainly because of the improvement in magnetocrystalline anisotropy. When the grain size increases to a critical value $\left(\mathrm{D}_{\mathrm{c}}\right)$ between the dual- and mono-domain states, $\mathrm{H}_{\mathrm{c}}$ reaches a maximum. The domain structure changes from the mono-domain state to the dual- or multi-domain state as the grain size exceeds $\mathrm{D}_{\mathrm{c}}$. Accordingly, the magnetization mechanism changes from domain rotation to domain wall movement and the $\mathrm{H}_{\mathrm{c}}$ decreases with an increase in grain size [40]. Therefore, we inferred that the $D_{c}$ between dual- and mono-domain states of the prepared NiZn ferrite was $\sim 450 \mathrm{~nm}$.

The Curie temperatures $\left(T_{c}\right)$ at the center of the prepared samples are shown in Table 1 . The $T_{c}$ of the sintered samples varied from $503^{\circ} \mathrm{C}$ to $522^{\circ} \mathrm{C}$, which showed only a small difference. $\mathrm{T}_{\mathrm{c}}$ is one of the intrinsic parameters of ferromagnetic materials. It is only related to the chemical composition and crystal structure of the materials, and is almost independent of grain size, orientation, and stress distribution. The main phase of all sintered samples was the NiZn ferrite with good crystallization, so the $T_{c}$ of the sintered samples was similar. The slight difference in sample $T_{c}$ was mainly attributed to the small fluctuation in phase composition that was caused by the decomposition of a small amount of NiZn ferrite and $\mathrm{Zn}$ volatilization during sintering. The $\mathrm{T}_{\mathrm{c}}$ of the sintered sample was lower than that of nickel ferrite $\left(587^{\circ} \mathrm{C}\right)[41]$, which was attributed to the nonmagnetic $\mathrm{Zn}^{2+}$ in the NiZn ferrite. The nonmagnetic $\mathrm{Zn}^{2+}$ ions that occupied A-sites in the NiZn ferrite reduced the superexchange between the A-B sublattices, which resulted in a decrease in sample $\mathrm{T}_{\mathrm{c}}$.

\section{Conclusions}


The dense NiZn ferrite ceramics were prepared using the UPECS method, during which the sample was kept above $600^{\circ} \mathrm{C}$ for no more than $90 \mathrm{~s}$. The conclusions obtained from this work were as follows:

(1) Grain growth and densification of the NiZn ferrite were accelerated, which benefited from the synergistic effect of the energy concentration of pulse current and joule heating of the sample.

(2) The difference in grain size between the edge and center of the samples that were prepared by the UPECS method originated from the uneven temperature distribution and current distribution in a sintering sample. The low heating rate and sintering temperature favored NiZn ferrite formation with a high density and ultrafine grains by the UPECS method.

(3) The slight differences in $M_{s}$ and $T_{c}$ of the prepared samples were mainly attributed to the small fluctuation of phase composition that was caused by the decomposition of a small amount of $\mathrm{NiZn}$ ferrite and $\mathrm{Zn}$ volatilization during sintering. The nonmagnetic $\mathrm{Zn}^{2+}$ ions that occupied A-sites reduced the superexchange interaction between A- and B-sublattices, which decreased the $\mathrm{T}_{\mathrm{c}}$ of the prepared sample.

(4) According to the grain size dependence of $\mathrm{H}_{\mathrm{c}}$, it was inferred that the critical grain size between the dual- and mono-domain states of the sintered NiZn ferrite may be $\sim 450 \mathrm{~nm}$.

\section{Acknowledgements}

This study was supported by the Project of State Key Laboratory of Environment-Friendly Energy Materials, Southwest University of Science and Technology (No. 20fksy23).

\section{References}

[1] Snelling EC. Soft ferrites: properties and applications. London: Butterworth and Co Ltd, 1988.

[2] Adam JD, Davis LE, Dionne GF, et al. Ferrite devices and materials. Ieee T Microw Theory 2002, 50: $721-737$.

[3] Kulikowski J. Soft magnetic ferrites - development or stagnation? J Magn Magn Mater 1984, 41: 56-62.

[4] Harris VG, Geiler A, Chen Y, et al. Recent advances in processing and applications of microwave ferrites. J Magn Magn Mater 2009, 321: 2035-2047.

[5] Silveyra JM, Ferrara E, Huber DL, et al. Soft magnetic materials for a sustainable and electrified world. Science 2018, 362: 2035-2047.

[6] Gao PZ, Hua X, Degirmenci V, et al. Structural and magnetic properties of $\mathrm{Ni}_{1-\mathrm{x}} \mathrm{Zn}_{\mathrm{x}} \mathrm{Fe}_{2} \mathrm{O}_{4}(\mathrm{x}=0,0.5$ and 1$)$ 
nanopowders prepared by sol-gel method. J Magn Magn Mater 2013, 348:44-50.

[7] Hossain AA, Mahmud ST, Seki M, et al. Structural, electrical transport, and magnetic properties of $\mathrm{Ni}_{1-\mathrm{x}} \mathrm{Zn}_{\mathrm{x}} \mathrm{Fe}_{2} \mathrm{O}_{4}$. J Magn Magn Mater 2007, 312: 210-219.

[8] Mathew DS, Juang RS. An overview of the structure and magnetism of spinel ferrite nanoparticles and their synthesis in microemulsions. Chem Eng $J$ 2007, 129: 51-65.

[9] Néel L. Influence des fluctuations thermiques sur l'aimantation de grains ferromagnétiques très fins. C R Acad Sci 1949, 228: 663-666.

[10] Kaiser M. Influence of $\mathrm{V}_{2} \mathrm{O}_{5}$ ion addition on the conductivity and grain growth of Ni-Zn-Cu ferrites. Curr Appl Phys 2010, 10:975-984.

[11] Verma AD, Dinesh C. Processing of nickel-zinc ferrites via the citrate precursor route for high-frequency applications. J Am Ceram Soc 2005, 88: 519-523.

[12] Gómeza CAP, Menesesb CAB, Structural parameters and cation distributions in solid state synthesized Ni-Zn ferrites. Mat Sci Eng B-adv 2018, 236-237:48-55.

[13] Niu YH, Fu S, Zhang KB, et al. Synthesis, microstructure, and properties of high purity $\mathrm{Mo}_{2} \mathrm{TiAlC}_{2}$ ceramics fabricated by spark plasma sintering. J Adv Ceram 2020, 9: 759-768.

[14] Mamoru O. Sintering, consolidation, reaction and crystal growth by the spark plasma system (SPS). Mat Sci Eng A-struct 2020, A287: 183-188.

[15] Rahmani M, Mirzaee O, Tajally M, et al. A comparative study of synthesis and spark plasma sintering of YAG nano powders by different co-precipitation methods. Ceram Int 2018, 44: 10035-10046.

[16] Wang SW, Chen LD, Kang YS, et al. Effect of plasma activate sintering (PAS) parameters on densification of copper powder. Mater Res Bull 2000, 35:619-628.

[17] Qin Y, Liu JX, Li F, et al. A high entropy silicide by reactive spark plasma sintering. J Adv Ceram 2019, 8: 148152.

[18] Liu GX, Dai B, Ren Y, et al. Microstructure and magnetic properties of $\mathrm{Ni}_{0.75} \mathrm{Zn}_{0.25} \mathrm{Fe}_{2} \mathrm{O}_{4}$ ferrite prepared using an electric current-assisted sintering method. Ceram Int 2021, 47: 11951-11957.

[19] Jesus, LM, Silva, RS, M'Peko JC. Ultrafast synthesis and sintering of materials in a single running experiment approach by using electric fields. $J$ Adv Ceram 2019, 8: 265-277.

[20] Biesuz M, Sglavo VM. Flash sintering of ceramics. J Eur Ceram Soc 2019, 39: 115-143.

[21] Avila V, Raj R. Flash sintering of ceramic films: The influence of surface to volume ratio. J Am Ceram Soc 2019, 102: 3063-3069.

[22] Gao Y, Liu FZ, Liu DG, et al. Electrical-field induced nonlinear conductive behavior in dense zirconia ceramic. $J$ Mater Sci Technol 2017, 33: 897-900.

[23] Guillon O, Gonzalez-Julian J, Dargatz B, et al. Field-assisted sintering technology/spark plasma sintering: mechanisms, materials, and technology developments. Adv Eng Mater 2014, 16: 830-849.

[24] Foong LK, Lyu ZJ. Sintering and mechanical behavior of SiC and WC co-added TiC-based composites densified by hot-pressing. Ceram Int 2021, 47: 6479-6486.

[25] Fang Y, Liu XH, Feng YX, et al. Microstructure and mechanical properties of $\mathrm{Ti}_{3}(\mathrm{Al}, \mathrm{Ga}) \mathrm{C}_{2} / \mathrm{Al}_{2} \mathrm{O}_{3}$ composites prepared by in situ reactive hot pressing. J Adv Ceram 2020, 9: 782-790.

[26] Zhang GP, Wang GF, Yang T H, et al. Synthesis and characterisation of TiC reinforced CoCrFeNi composite by 
hot-pressing sintering. Mater Sci Tech-lond 2020, 36: 409-416.

[27] Zhu ZY, Yin ZB, Hong DB, et al. Preparation of complex-shaped $\mathrm{Al}_{2} \mathrm{O}_{3} / \mathrm{SiCp} / \mathrm{SiCw}$ ceramic tool by two-step microwave sintering. Ceram Int 2020 46: 27362-27372.

[28] Orlik K, Lorgouilloux Y, Marchet P, et al. Influence of microwave sintering on electrical properties of BCTZ lead free piezoelectric ceramics. J Eur Ceram Soc 2020, 40: 1212-1216.

[29] Liu Y, Yi ZG, Li JJ, et al. Microwave sintering of nanocrystalline $\mathrm{Ni}_{1-\mathrm{x}} \mathrm{Zn}_{\mathrm{x}} \mathrm{Fe}_{2} \mathrm{O}_{4}$ ferrite powder and their magnetic properties. J Am Ceram Soc 2013, 96: 151-156.

[30] Gil-Flores L, Salvador MD, Penaranda-Foix FL, et al. Microstructure and mechanical properties of $5.8 \mathrm{GHz}$ microwave-sintered $\mathrm{ZrO}_{2} / \mathrm{Al}_{2} \mathrm{O}_{3}$ ceramics. Ceram Int 2019, 45: 18059-18064.

[31] Chen YQ, Fan BB, Shao G, et al. Preparation of large size ZTA ceramics with eccentric circle shape by microwave sintering. J Adv Ceram 2016, 5: 291-297.

[32] Raj R. Joule heating during flash-sintering. J Eur Ceram Soc 2012, 32: 2293-2301.

[33] Langford BJI, Wilson AJC. Scherrer after Sixty Years: A survey and some new results in the determination of crystallite size. J Appl Crystallogr 1978, 11: 102-113.

[34] Nelson JB, Riley DP. An experimental investigation of extrapolation methods in the derivation of accurate unit-cell dimensions of crystals. Proceedings of the Physical Society 1945, 57: 160-177.

[35] Guo SJ. Powder sintering theory. Beijing: Metallurgical Industry Press, 1998.

[36] Sellars CM, Whiteman JA. Recrystallization and grain growth in hot rolling. Met Sci 1979, 13:187-194.

[37] Jane GC, Das BK, Goel NC. Effect of $\mathrm{MoO}_{3}$ addition on the grain growth kinetics of a Mn-Zn ferrite. J Am Ceram Soc 1979, 62:79-85.

[38] Zhou DX, Zhang XL, Li BR, et al. Semiconductor ceramics and its application. Wuhan: Huazhong University of Science and Technology Press, 1991.

[39] Stoner EC, Wohlfarth EP. A mechanism of magnetic hysteresis in heterogeneous alloys. Ieee T Magn 1991, 27: $3475-3518$.

[40] Zhao LJ, Yang H, Cui YM, et al. Study of preparation and magnetic properties of silica-coated cobalt ferrite nanocomposites. J Mater Sci 2007, 42: 4110-4114.

[41] Yuan DF, Ma DL. Magnetophysics. Chendu: University of Electronic Science and Technology of China Press, 1994. 


\section{Figure captions}

Figure 1 Schematic of a graphite die-punches setup used in the UPECS method.

Figure 2 Sintering process diagrams of NiZn ferrite using (a) UPECS and (b) traditional sintering

Figure 3 XRD patterns of samples prepared by UPECS at different (a) sintering temperatures and (b) heating rates.

Figure 4 SEM images of (a)-(e) the edge and (f)-(j) the center of samples sintered at different temperatures through UPECS.

Figure 5 SEM images showing (a)-(c) edge and (d)-(f) center of samples sintered at different heating rates through UPECS.

Figure 6 Schematic diagram of current flow path at (a) early, and (b) intermediate and final stages of sintering.

Figure 7 Schematic diagram of (a) current flow through particles and (b) "neck" formation between particles on the base of Joule heating.

Figure 8 Average grain size of samples sintered at different (a) temperatures and (b) heating rates by UPECS.

Figure 9 XRD patterns of samples sintered by UPECS and traditional method.

Figure 10 SEM images showing center of samples sintered by (a), (b) UPECS and (c), (d) traditional method.

Figure 11 Hysteresis loops of samples prepared at different (a) sintering temperatures and (b) different heating rates by UPECS.

Figure 12 Grain size dependence of coercivity of prepared ceramics. 
Figure 1

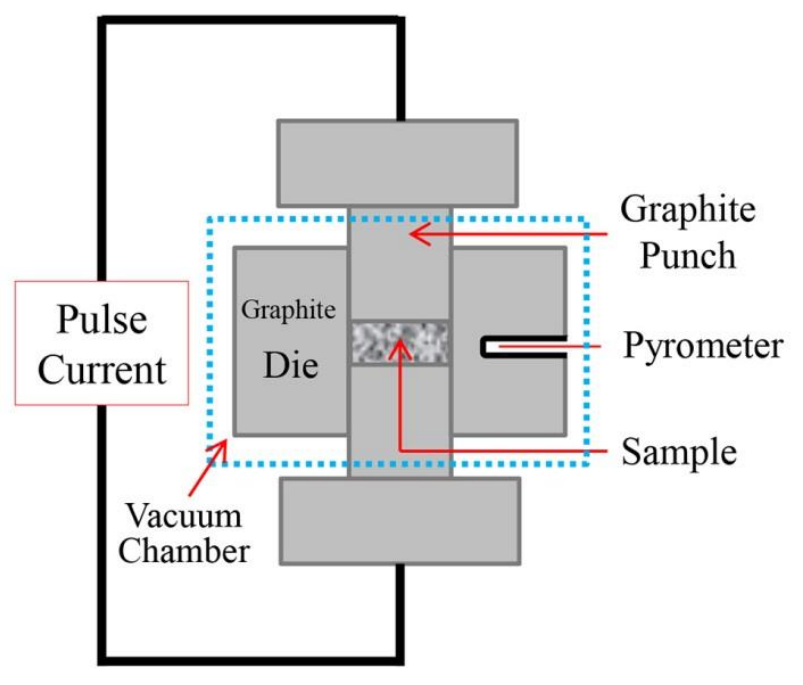


Figure 2
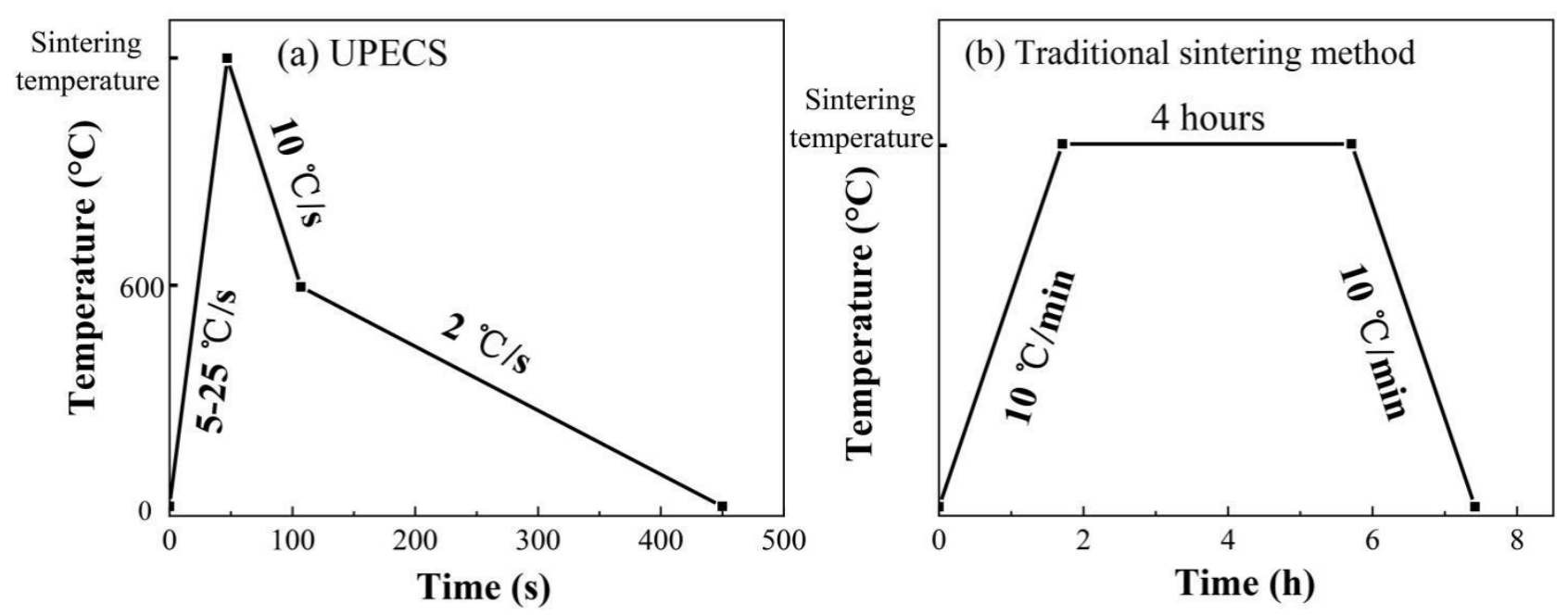
Figure 3
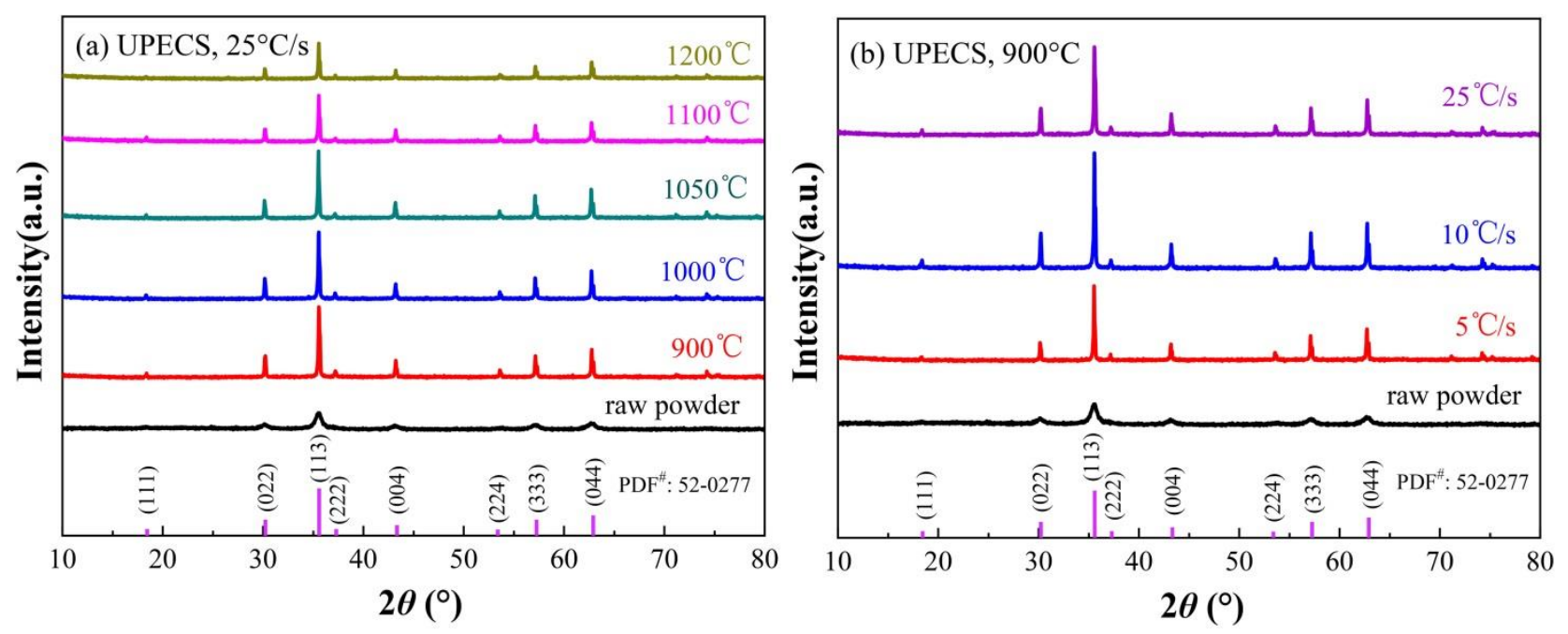
Figure 4

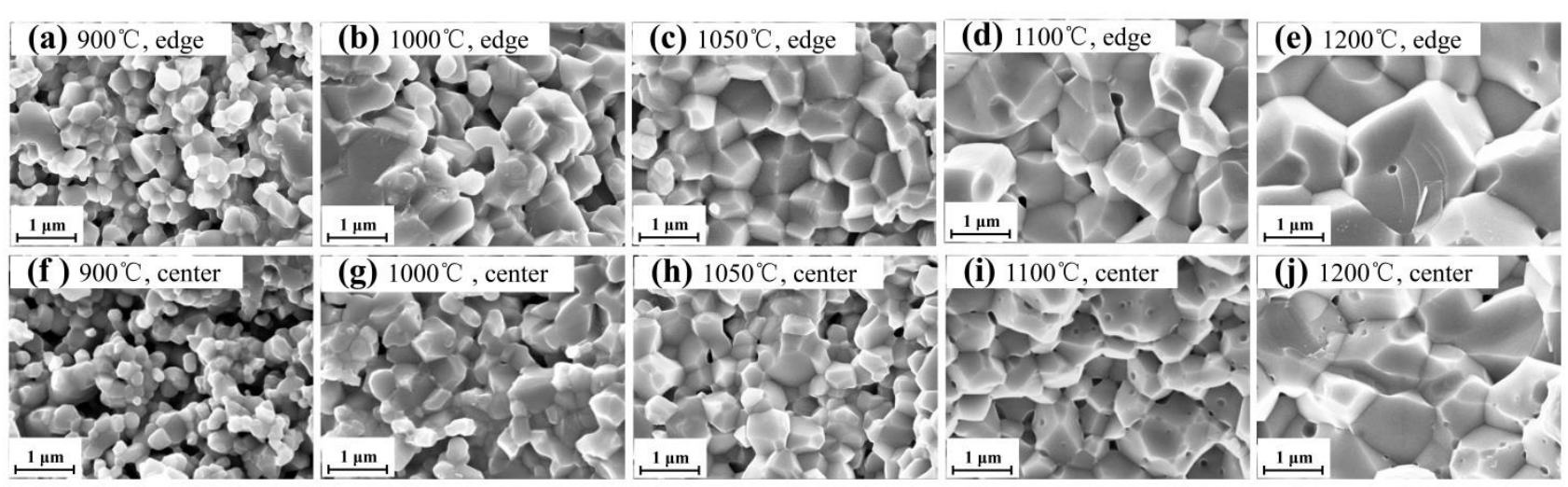




\section{Figure 5}

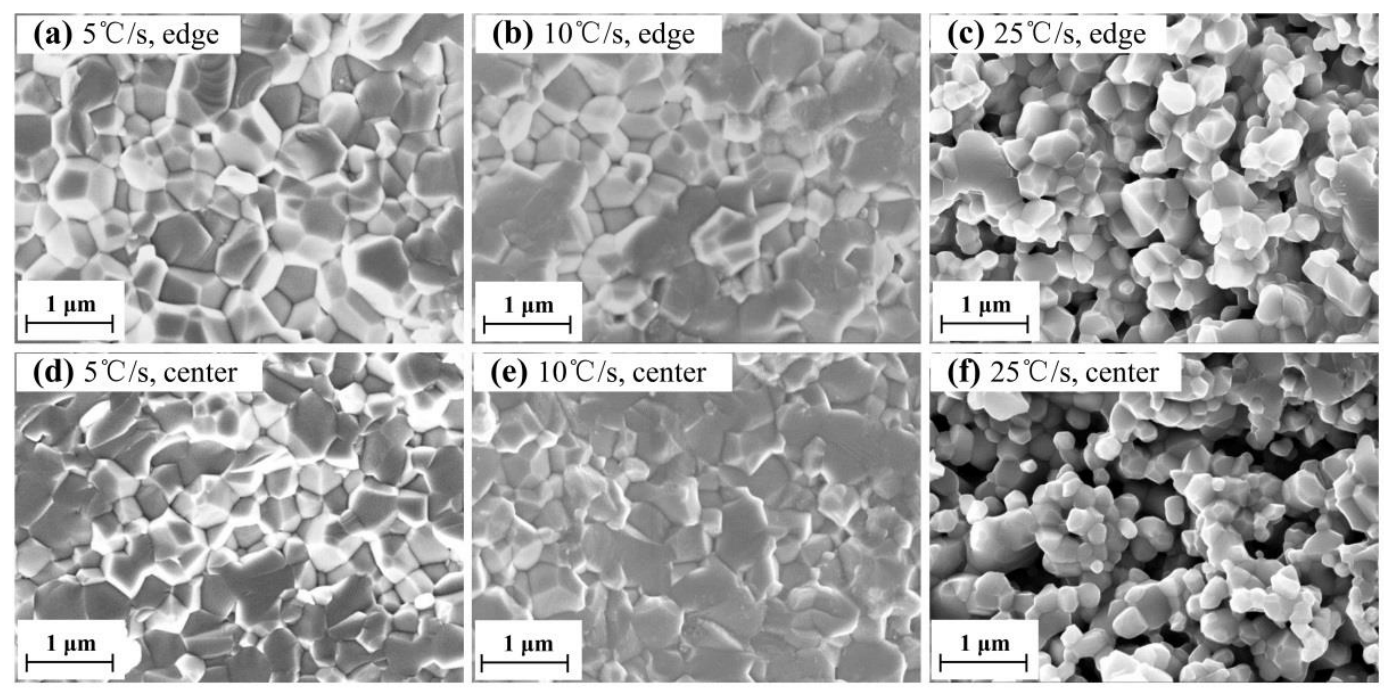


Figure 6

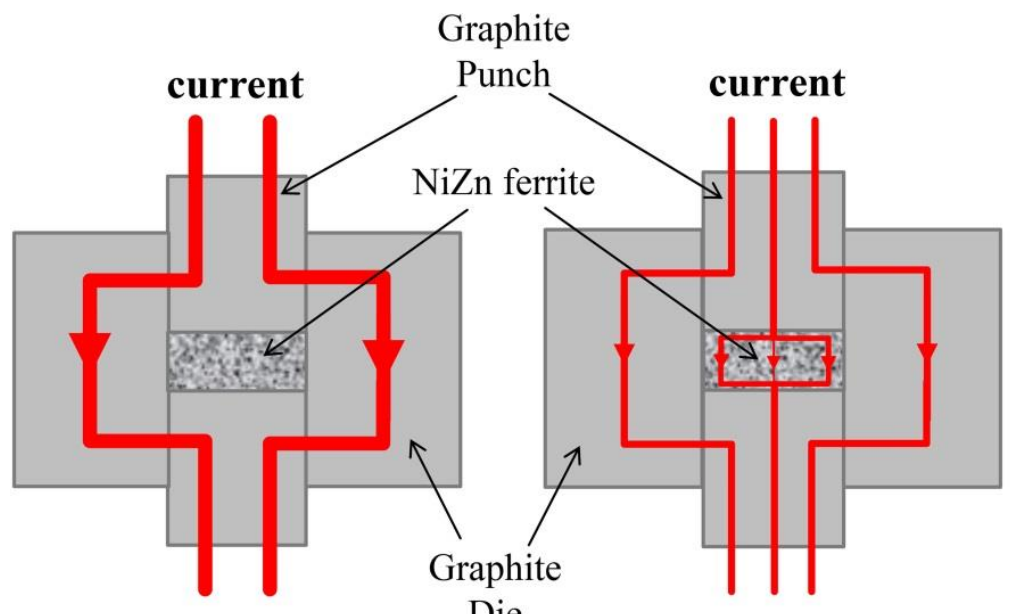

(a)

(b) 
Figure 7

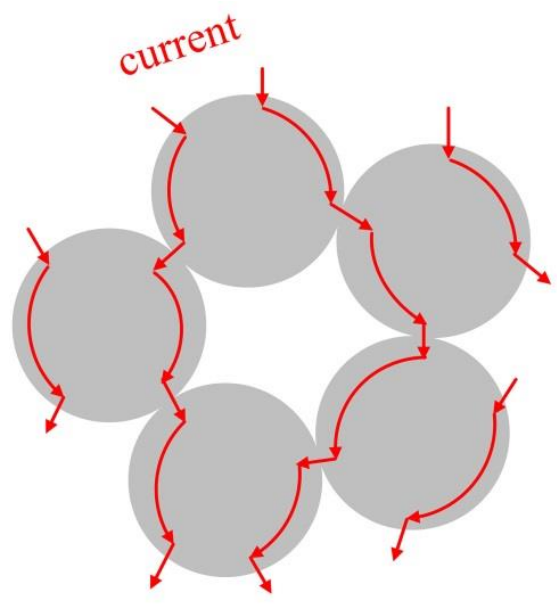

(a)

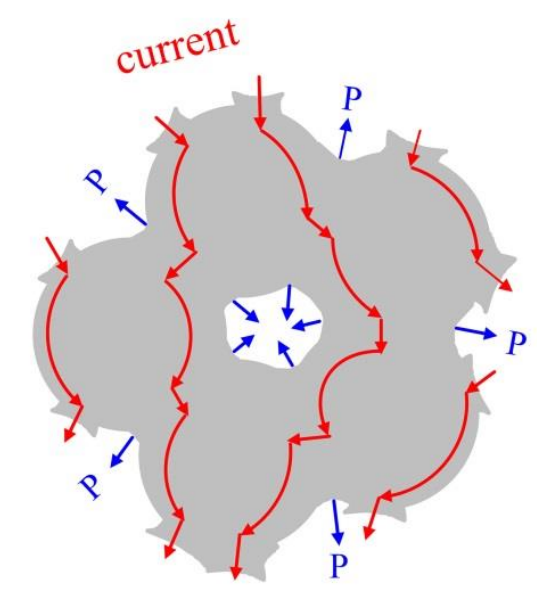

(b) 
Figure 8
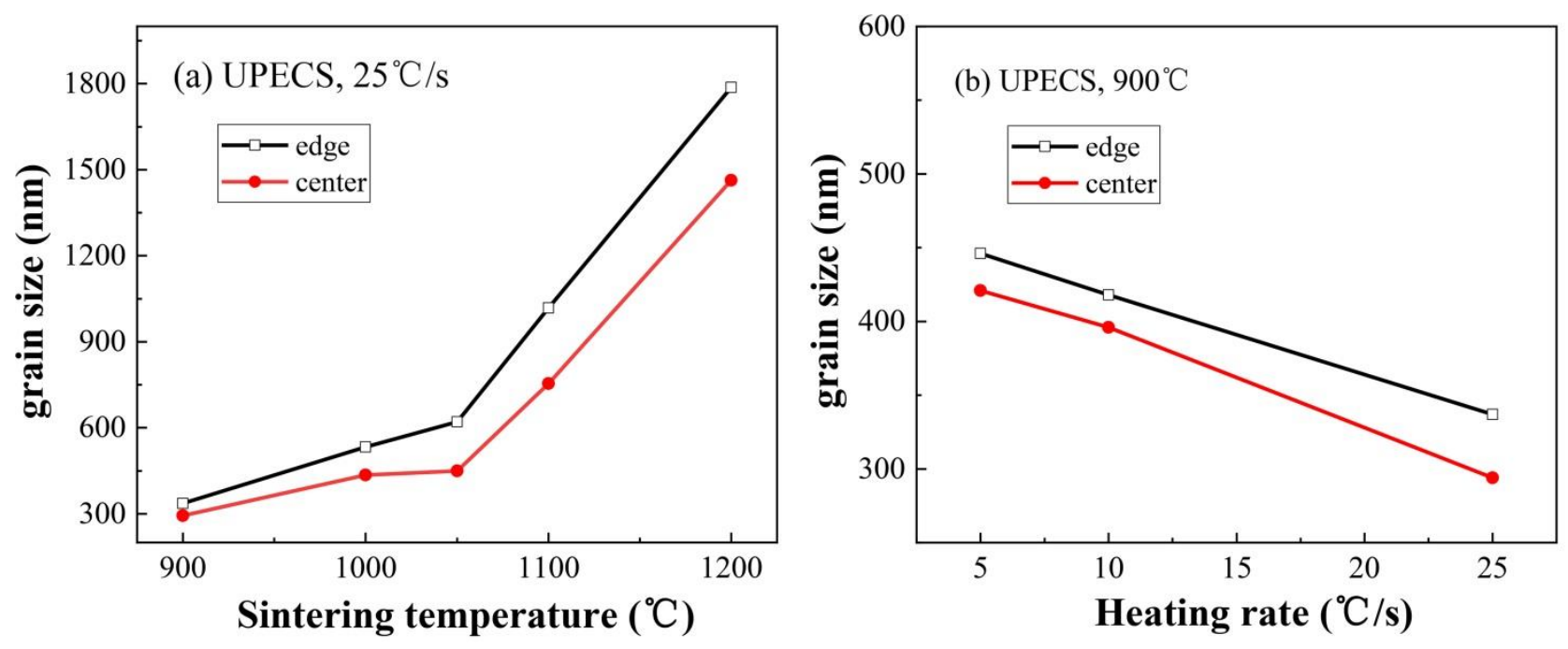
Figure 9

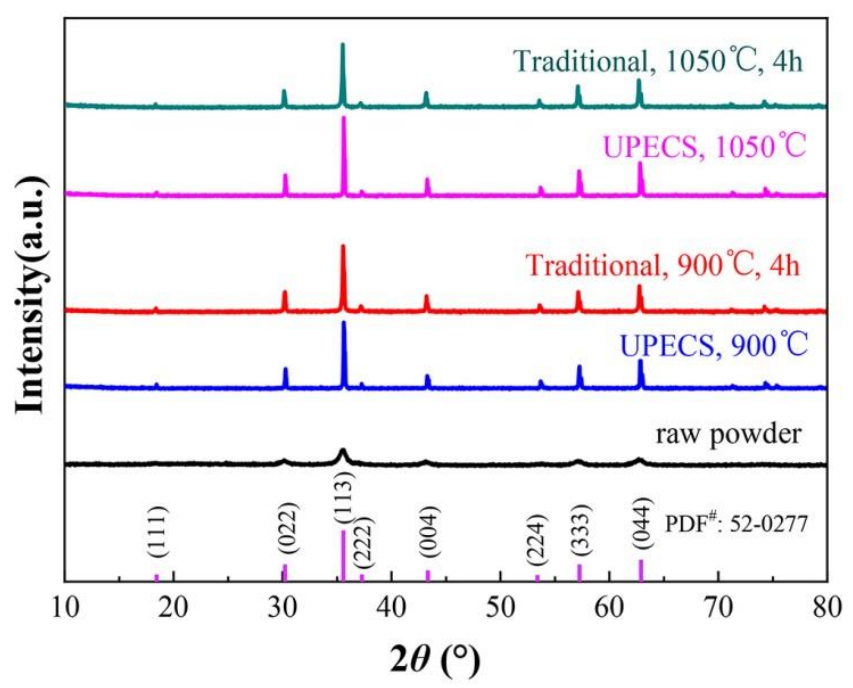


Figure 10

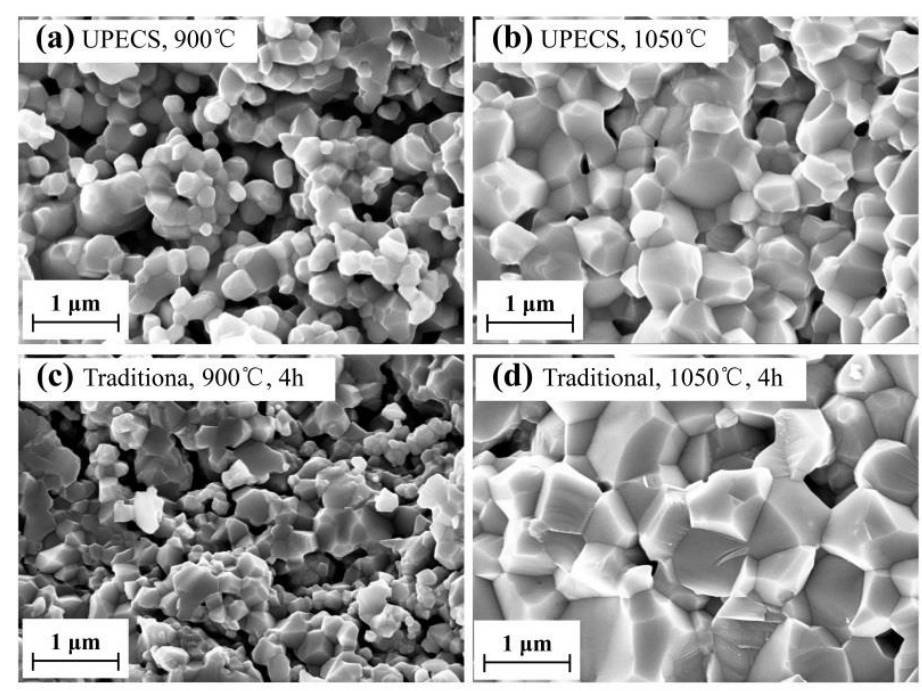


Figure 11
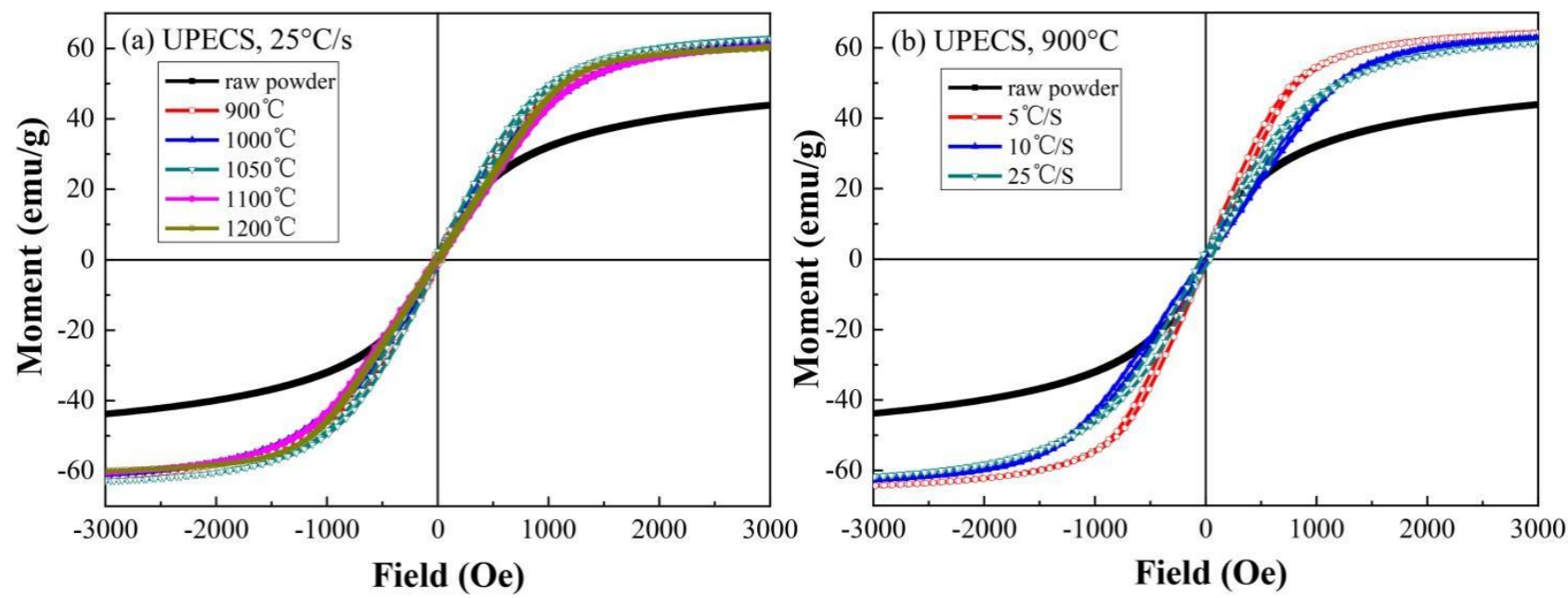
Figure 12

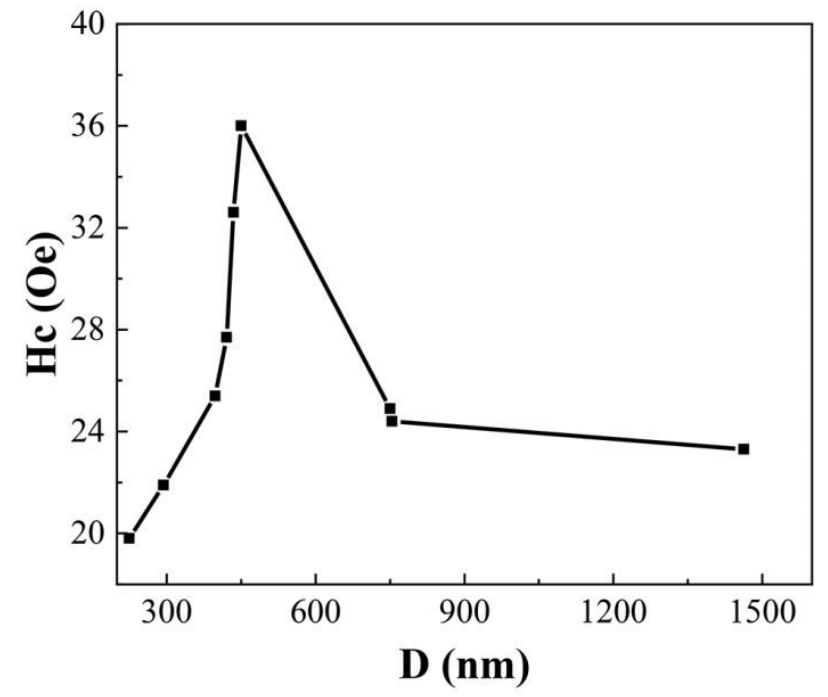


Table 1 Sintering conditions, lattice constant, average grain size, density, porosity and magnetic properties of NiZn ferrites

\begin{tabular}{|c|c|c|c|c|c|c|c|c|c|c|c|c|c|}
\hline \multirow{2}{*}{ Sintering method } & \multirow{2}{*}{$\begin{array}{c}\text { Molding } \\
\text { pressure } \\
(\mathrm{MPa}) / \mathrm{dwell} \\
\text { time (min) } \\
\end{array}$} & \multirow{2}{*}{$\begin{array}{c}\text { Heating } \\
\text { rate }\end{array}$} & \multirow{2}{*}{$\begin{array}{c}\text { Sintering } \\
\text { temperature } \\
\left({ }^{\circ} \mathbf{C}\right)\end{array}$} & \multirow{2}{*}{$\begin{array}{l}\text { Duration } \\
\text { time not } \\
\text { less than } \\
600^{\circ} \mathrm{C}\end{array}$} & \multirow{2}{*}{$\begin{array}{c}\text { Lattice } \\
\text { constant } \\
\text { (̊) }\end{array}$} & \multicolumn{2}{|c|}{$\begin{array}{l}\text { Average grain } \\
\text { size }(\mathbf{n m})\end{array}$} & \multirow{2}{*}{$\begin{array}{l}\text { Density } \\
\left(\mathrm{g} / \mathrm{cm}^{3}\right)\end{array}$} & \multirow{2}{*}{$\begin{array}{c}\text { Porosity } \\
(\%)\end{array}$} & \multicolumn{4}{|c|}{ Magnetic properties } \\
\hline & & & & & & Edge & Center & & & $\begin{array}{c}\mathrm{M}_{\mathrm{s}} \\
(\mathrm{emu} / \mathrm{g})\end{array}$ & $\begin{array}{c}M_{r} \\
(e m u / g)\end{array}$ & $\begin{array}{c}\mathbf{H}_{\mathbf{c}} \\
(\mathrm{Oe})\end{array}$ & $\begin{array}{c}\mathbf{T}_{\mathbf{c}} \\
\left({ }^{\circ} \mathbf{C}\right)\end{array}$ \\
\hline Raw powder & -- & -- & -- & -- & 8.366 & -- & -- & -- & -- & 43.9 & 0.2 & 0.2 & 498 \\
\hline UPECS & $60 / 1$ & $25^{\circ} \mathrm{C} / \mathrm{s}$ & 900 & $42 \mathrm{~s}$ & 8.370 & 337 & 294 & 4.49 & 16.06 & 61.6 & 2.2 & 21.9 & 522 \\
\hline UPECS & $60 / 1$ & $25^{\circ} \mathrm{C} / \mathrm{s}$ & 1000 & $56 \mathrm{~s}$ & 8.366 & 533 & 435 & 4.78 & 10.64 & 61.3 & 1.3 & 32.6 & 513 \\
\hline UPECS & $60 / 1$ & $25^{\circ} \mathrm{C} / \mathrm{s}$ & 1050 & $63 \mathrm{~s}$ & 8.370 & 621 & 450 & 4.86 & 9.14 & 63.0 & 2.1 & 36.0 & 505 \\
\hline UPECS & $60 / 1$ & $25^{\circ} \mathrm{C} / \mathrm{s}$ & 1100 & $70 \mathrm{~s}$ & 8.369 & 1018 & 754 & 4.71 & 11.95 & 60.6 & 1.2 & 24.4 & 511 \\
\hline UPECS & $60 / 1$ & $25^{\circ} \mathrm{C} / \mathrm{s}$ & 1200 & $84 \mathrm{~s}$ & 8.367 & 1787 & 1463 & 5.12 & 4.28 & 60.1 & 1.2 & 23.3 & 503 \\
\hline UPECS & $60 / 1$ & $5^{\circ} \mathrm{C} / \mathrm{s}$ & 900 & $90 \mathrm{~s}$ & 8.370 & 456 & 421 & 5.11 & 4.47 & 62.9 & 3.8 & 27.7 & 503 \\
\hline UPECS & $60 / 1$ & $10^{\circ} \mathrm{C} / \mathrm{s}$ & 900 & $60 \mathrm{~s}$ & 8.370 & 410 & 398 & 5.09 & 4.84 & 62.8 & 1.3 & 25.4 & 504 \\
\hline UPECS & $60 / 1$ & $25^{\circ} \mathrm{C} / \mathrm{s}$ & 900 & $42 \mathrm{~s}$ & 8.370 & 337 & 294 & 4.49 & 16.06 & 61.6 & 2.2 & 21.9 & 522 \\
\hline Traditional method & $60 / 1$ & $10^{\circ} \mathrm{C} / \mathrm{min}$ & 900 & $300 \min$ & 8.367 & -- & 225 & 4.85 & 9.33 & 62.4 & 1.5 & 19.8 & 505 \\
\hline Traditional method & $60 / 1$ & $10^{\circ} \mathrm{C} / \mathrm{min}$ & 1050 & $315 \mathrm{~min}$ & 8.368 & -- & 750 & 5.01 & 6.34 & 64.0 & 1.1 & 24.9 & 512 \\
\hline
\end{tabular}

* Average grain size was estimated by a line intercept method on SEM image. 
Figures

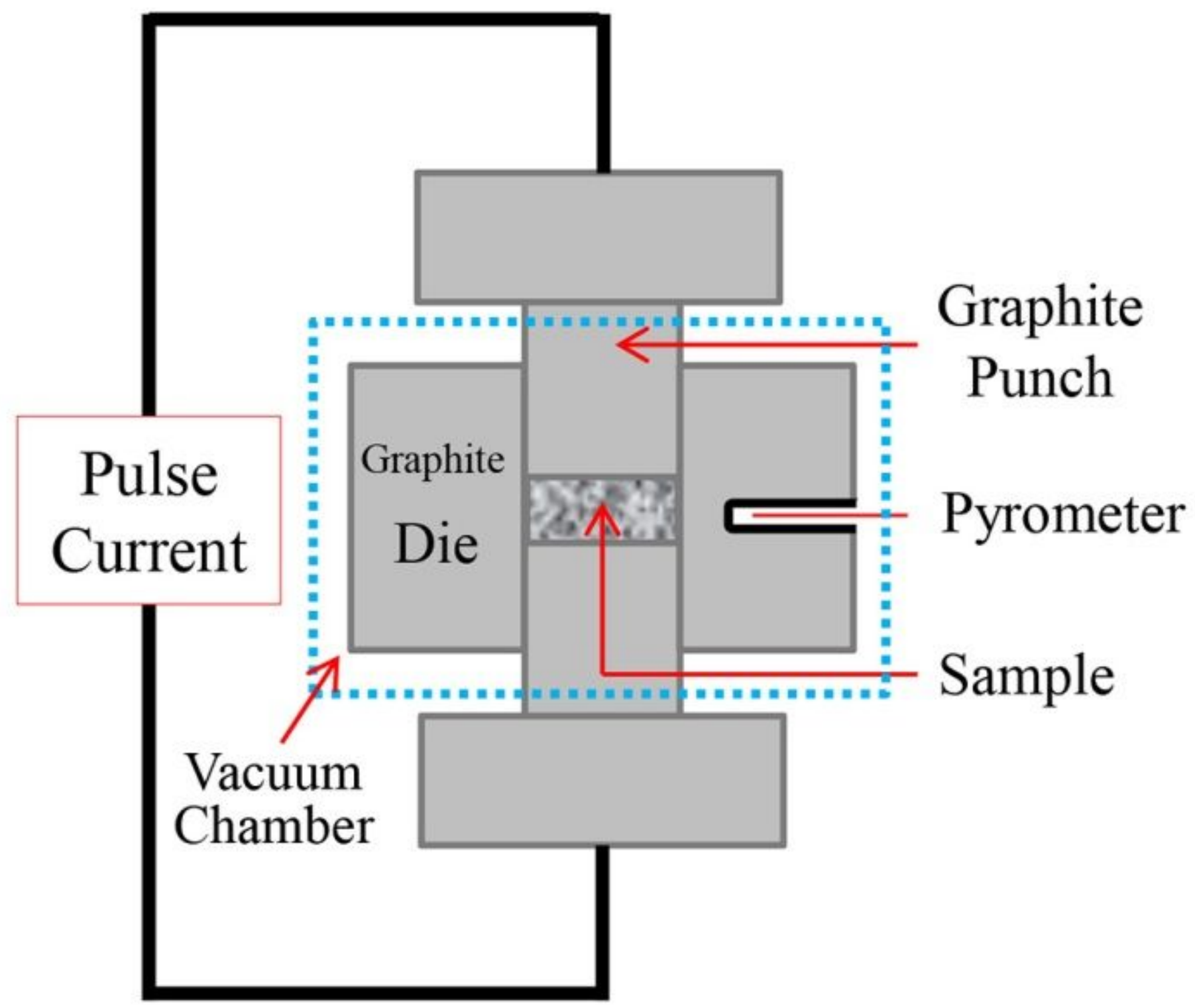

Figure 1

Schematic of a graphite die-punches setup used in the UPECS method. 

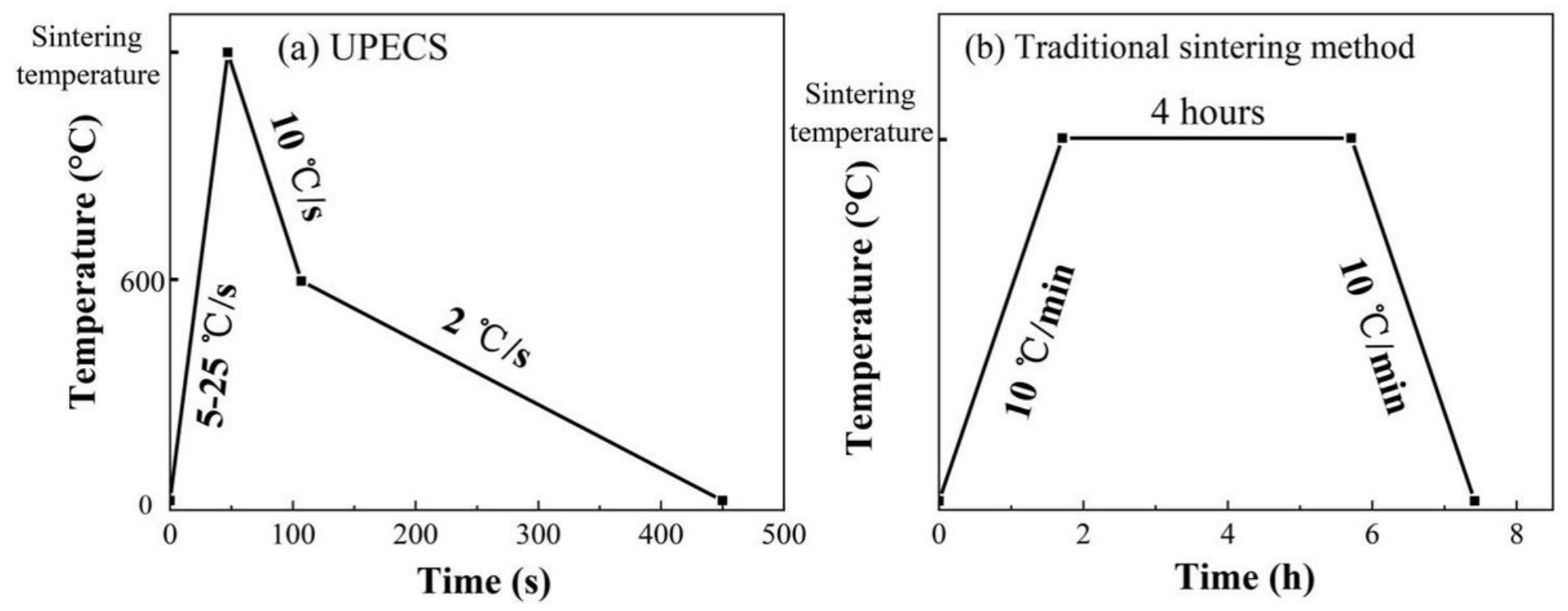

Figure 2

Sintering process diagrams of NiZn ferrite using (a) UPECS and (b) traditional sintering
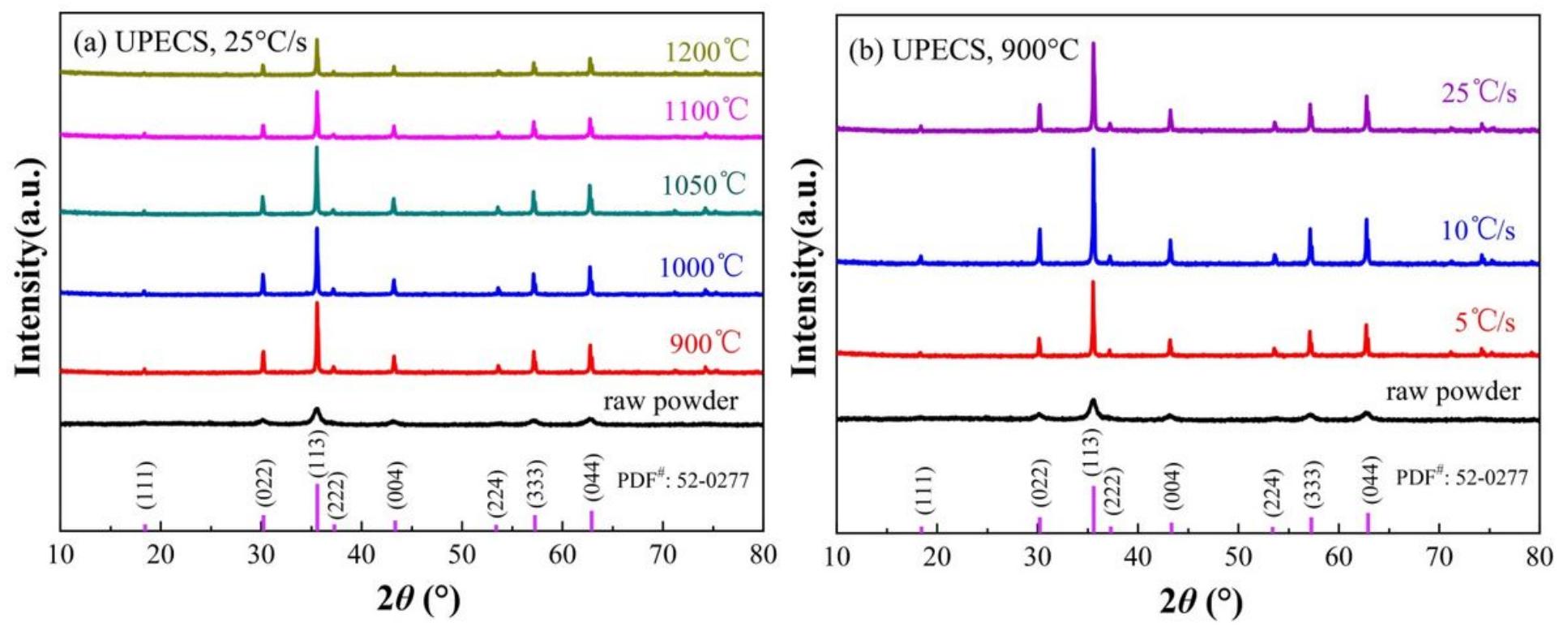

Figure 3

XRD patterns of samples prepared by UPECS at different (a) sintering temperatures and (b) heating rates. 

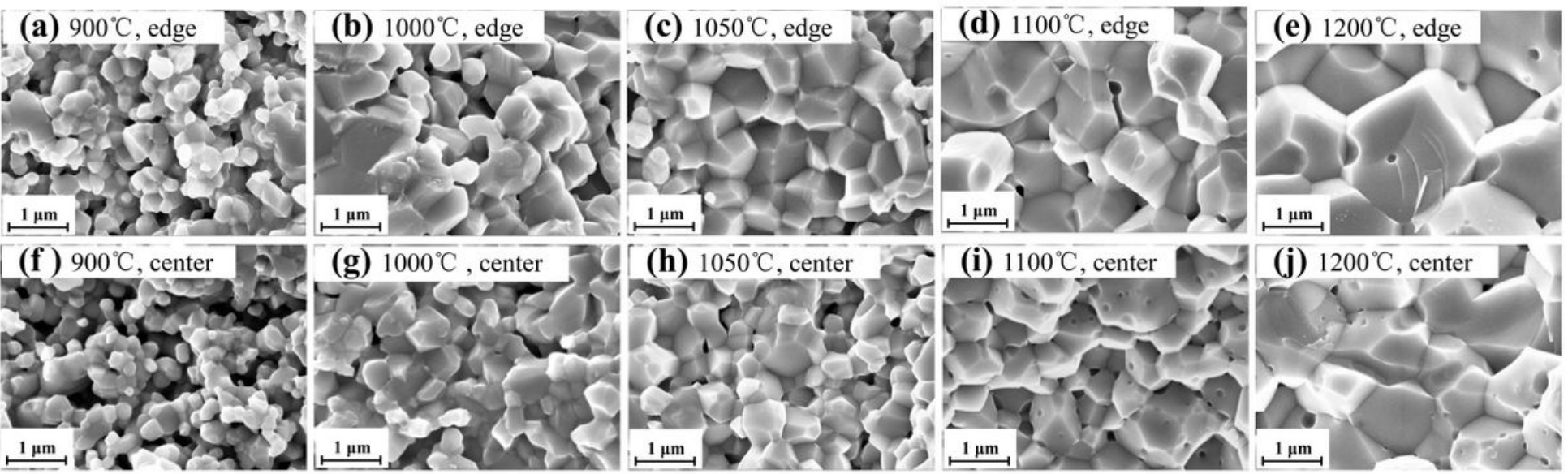

\section{Figure 4}

SEM images of $(a)-(e)$ the edge and $(f)-(j)$ the center of samples sintered at different temperatures through UPECS.
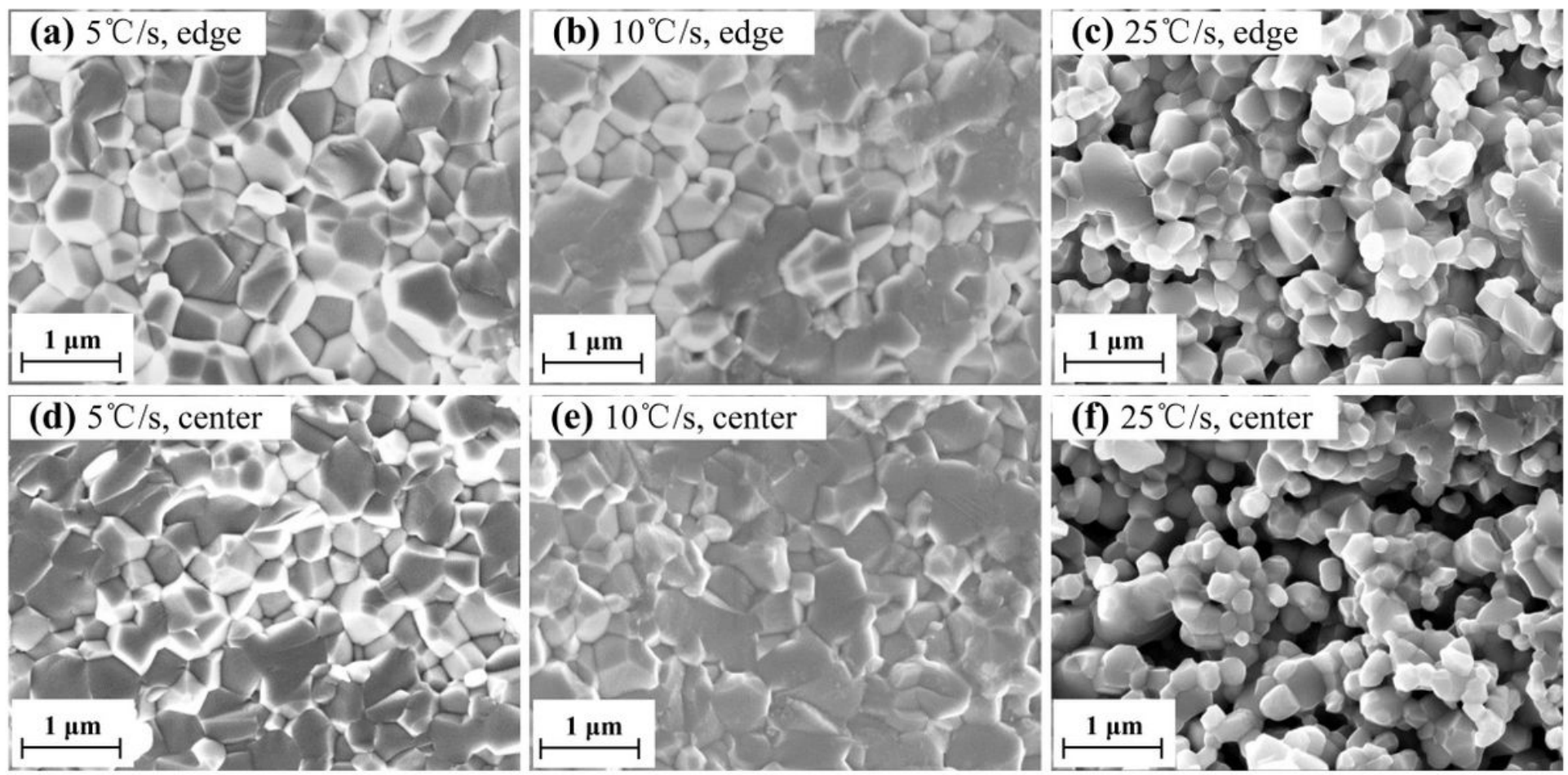

Figure 5

SEM images showing (a) - (c) edge and (d) - (f) center of samples sintered at different heating rates through UPECS. 


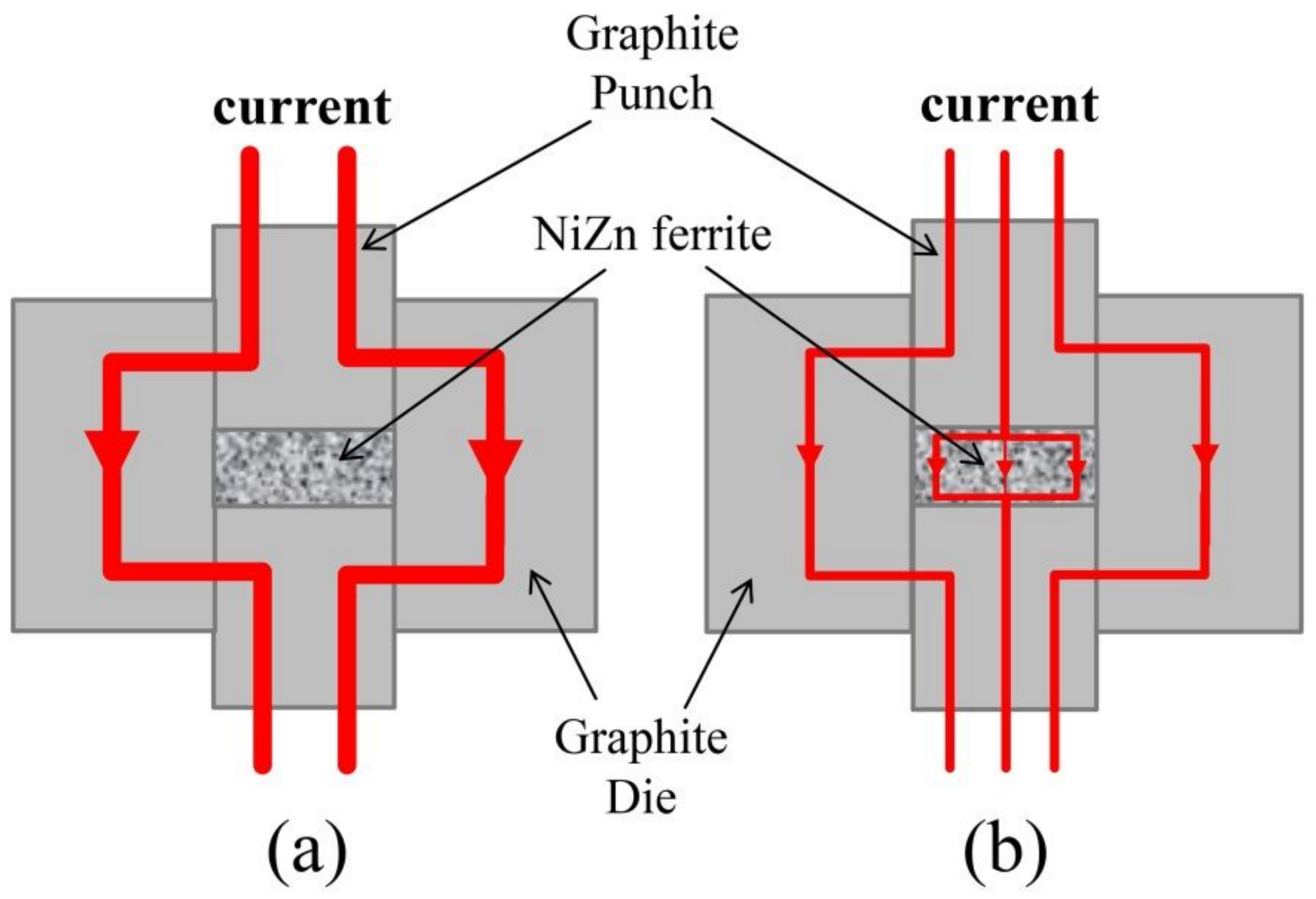

Figure 6

Schematic diagram of current flow path at (a) early, and (b) intermediate and final stages of sintering.
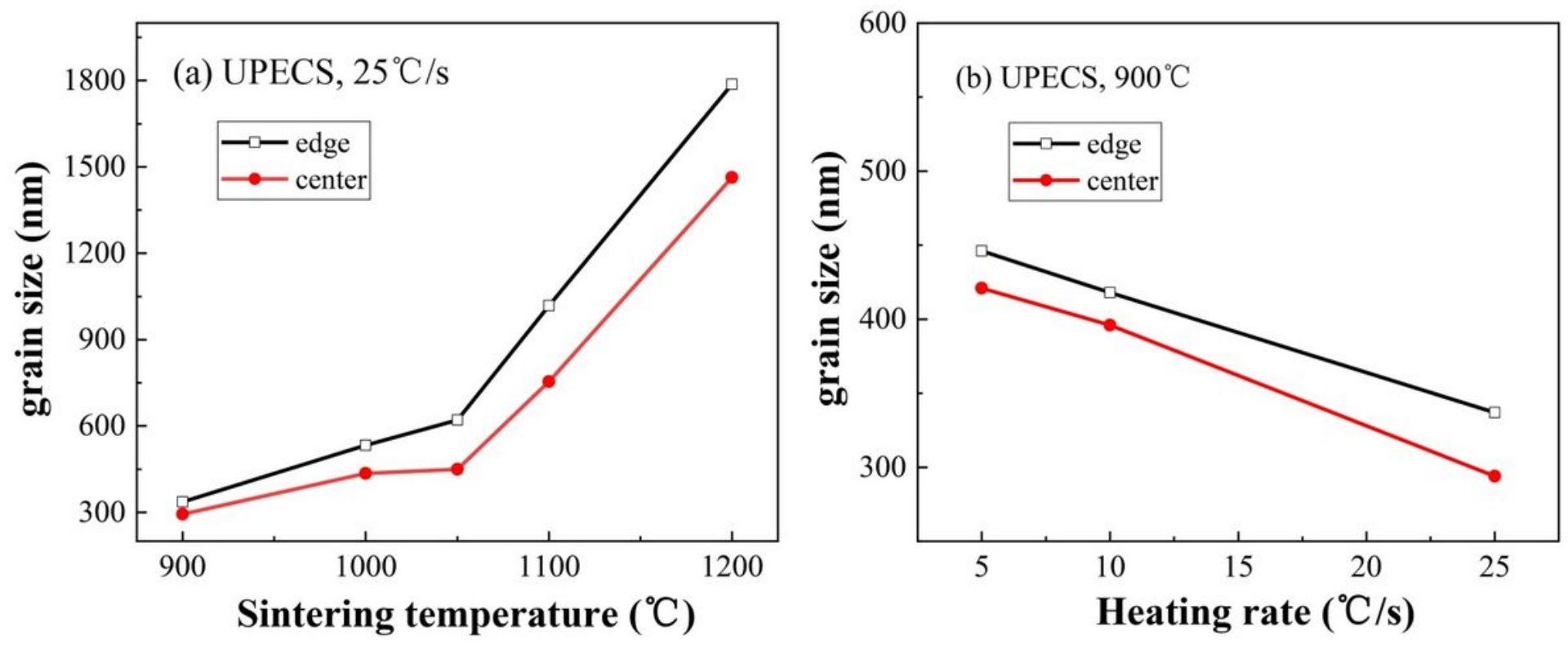

Figure 8 
Average grain size of samples sintered at different (a) temperatures and (b) heating rates by UPECS.

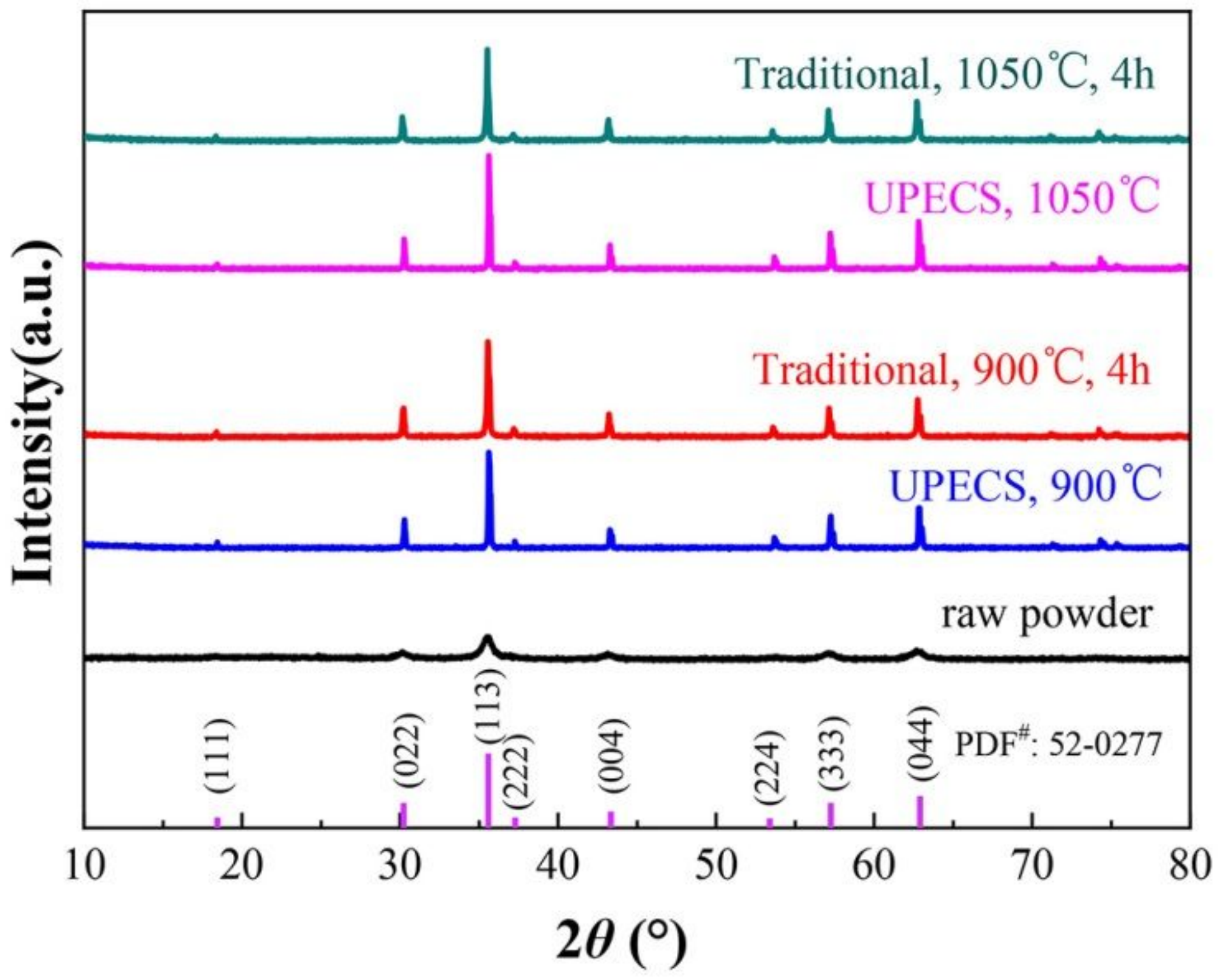

Figure 9

XRD patterns of samples sintered by UPECS and traditional method. 

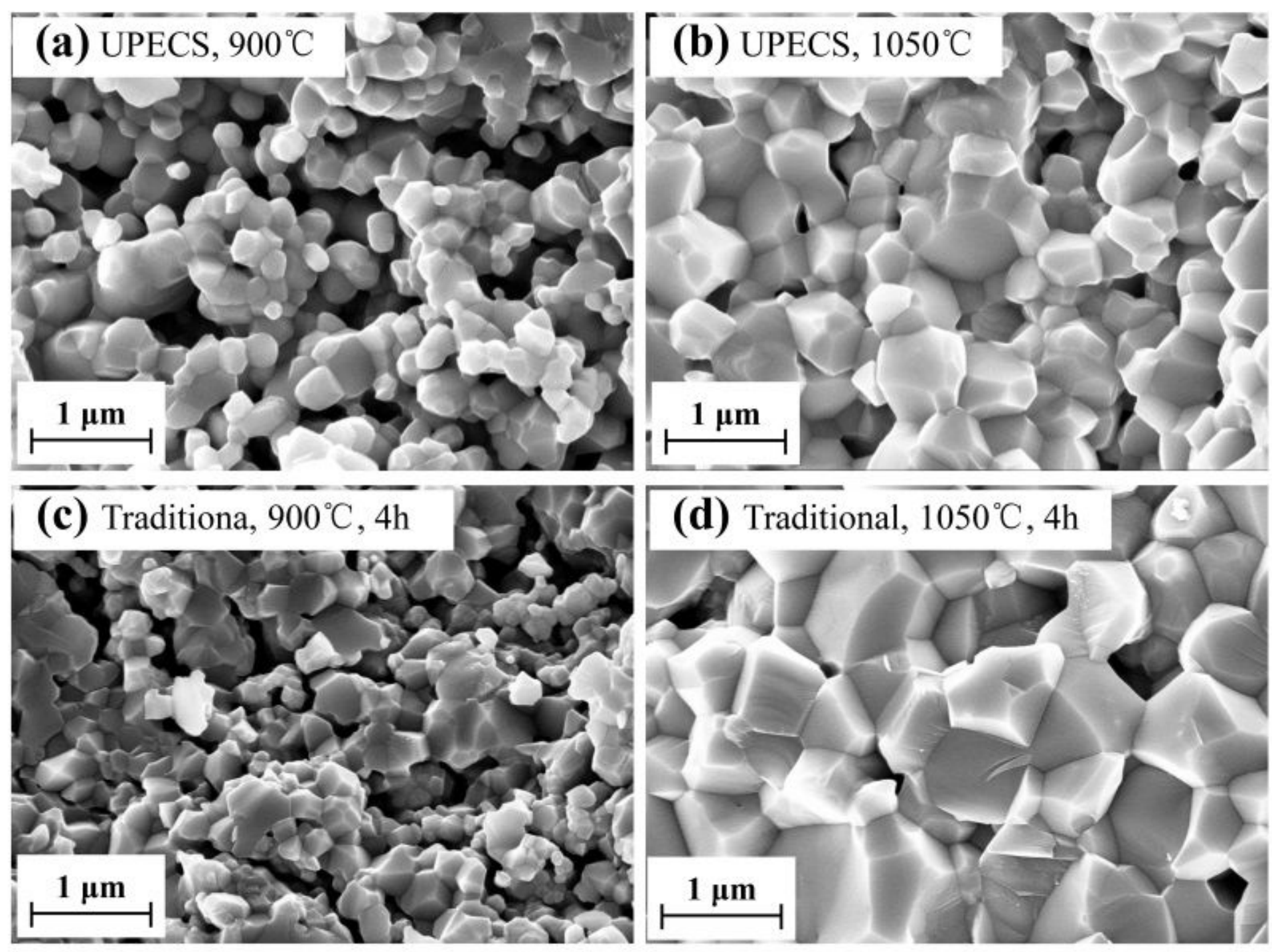

Figure 10

SEM images showing center of samples sintered by (a), (b) UPECS and (c), (d) traditional method.
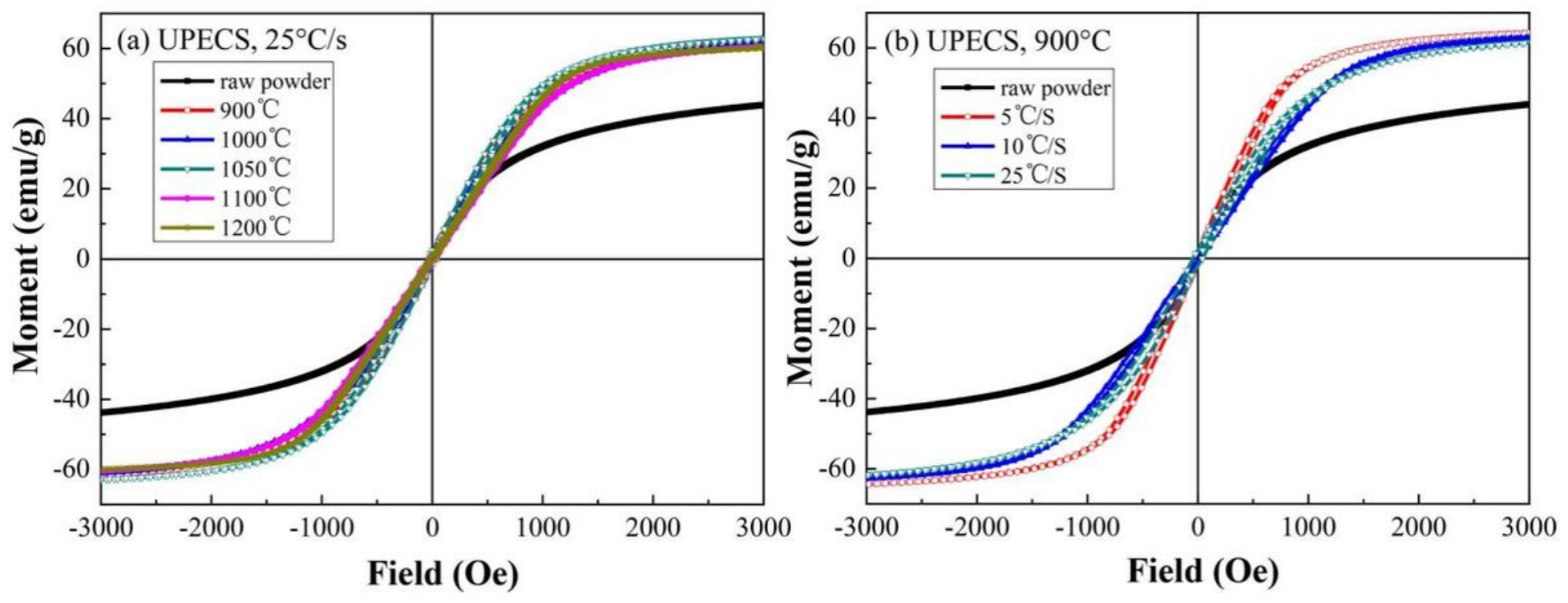
Figure 11

Hysteresis loops of samples prepared at different (a) sintering temperatures and (b) different heating rates by UPECS.

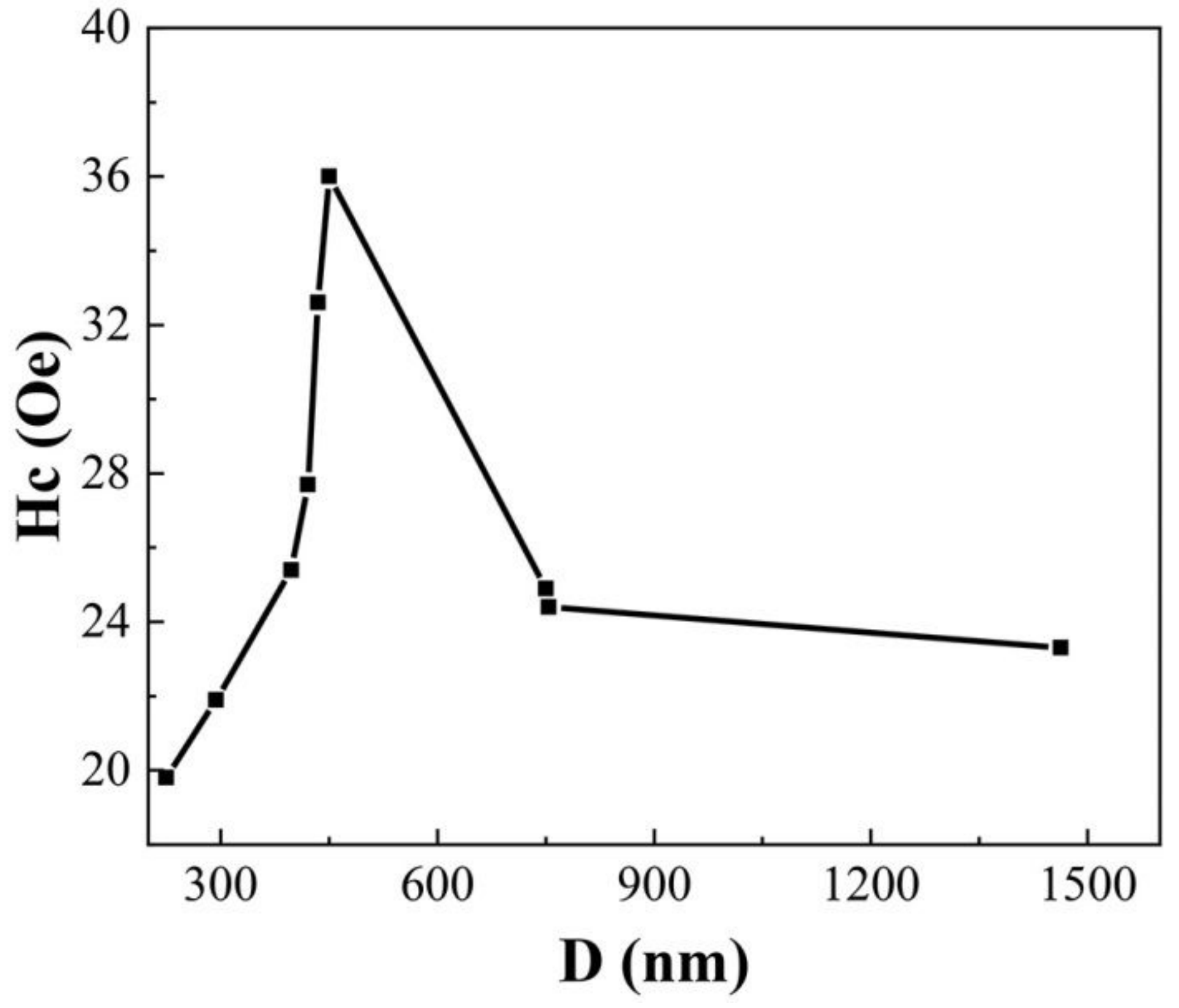

Figure 12

Grain size dependence of coercivity of prepared ceramics. 